\title{
Catecholaminergic Innervation of the Lateral Nucleus of the Cerebellum Modulates Cognitive Behaviors
}

\author{
Erik S. Carlson, ${ }^{1,2}$ Avery C. Hunker, ${ }^{3}$ Stefan G. Sandberg, ${ }^{1}$ Timothy M. Locke, ${ }^{3}$ Julianne M. Geller, ${ }^{2}$ \\ Abigail G. Schindler, ${ }^{2}$ Steven A. Thomas, ${ }^{5}$ Martin Darvas, ${ }^{4}$ Paul E. M. Phillips, ${ }^{1}$ and Larry S. Zweifel ${ }^{1,3}$ \\ ${ }^{1}$ Department of Psychiatry and Behavioral Sciences, University of Washington, Seattle, Washington $98195,{ }^{2}$ Geriatric Research, Education and \\ Clinical Center, Veteran's Affairs Medical Center, Puget Sound, Seattle, Washington $98108,{ }^{3}$ Department of Pharmacology, University of \\ Washington, Seattle, Washington 98195, ${ }^{4}$ Department of Pathology, University of Washington, Seattle, Washington 98195, and ${ }^{5}$ Department of \\ Pharmacology, University of Pennsylvania, Philadelphia, Pennsylvania 19104
}

The cerebellum processes neural signals related to rewarding and aversive stimuli, suggesting that the cerebellum supports nonmotor functions in cognitive and emotional domains. Catecholamines are a class of neuromodulatory neurotransmitters well known for encoding such salient stimuli. Catecholaminergic modulation of classical cerebellar functions have been demonstrated. However, a role for cerebellar catecholamines in modulating cerebellar nonmotor functions is unknown. Using biochemical methods in male mice, we comprehensively mapped $\mathrm{TH}^{+}$fibers throughout the entire cerebellum and known precerebellar nuclei. Using electrochemical (fast scan cyclic voltammetry), and viral/genetic methods to selectively delete Th in fibers innervating the lateral cerebellar nucleus (LCN), we interrogated sources and functional roles of catecholamines innervating the LCN, which is known for its role in supporting cognition. The LCN has the most $\mathrm{TH}^{+}$fibers in cerebellum, as well as the most change in rostrocaudal expression among the cerebellar nuclei. Norepinephrine is the major catecholamine measured in LCN. Distinct catecholaminergic projections to LCN arise only from locus coeruleus, and a subset of Purkinje cells that are positive for staining of TH. LC stimulation was sufficient to produce catecholamine release in LCN. Deletion of Th in fibers innervating LCN (LCN-Th-cKO) resulted in impaired sensorimotor integration, associative fear learning, response inhibition, and working memory in LCN-Th-cKO mice. Strikingly, selective inhibition of excitatory LCN output neurons with inhibitory designer receptor exclusively activated by designer drugs led to facilitation of learning on the same working memory task impaired in LCN-Th-cKO mice. Collectively, these data demonstrate a role for LCN catecholamines in cognitive behaviors.

Key words: cerebellum; fear conditioning; norepinephrine; tyrosine hydroxylase; voltammetry; working memory

Significance Statement

Here, we report on interrogating sources and functional roles of catecholamines innervating the lateral nucleus of the cerebellum (LCN). We map and quantify expression of TH, the rate-limiting enzyme in catecholamine synthesis, in the entire cerebellar system, including several precerebellar nuclei. We used cyclic voltammetry and pharmacology to demonstrate sufficiency of LC stimulation to produce catecholamine release in LCN. We used advanced viral techniques to map and selectively KO catecholaminergic neurotransmission to the LCN, and characterized significant cognitive deficits related to this manipulation. Finally, we show that inhibition of excitatory LCN neurons with designer receptor exclusively activated by designer drugs, designed to mimic Gi-coupled catecholamine GPCR signaling, results in facilitation of a working memory task impaired in LCN-specific TH KO mice.

\footnotetext{
Received Sep. 14, 2020; revised Jan. 12, 2021; accepted Jan. 16, 2021

Author contributions: E.S.C., S.G.S., A.G.S., and L.S.Z. designed research; E.S.C., A.C.H., S.G.S., T.M.L., J.M.G., and A.G.S. performed research; E.S.C., A.C.H., S.G.S., T.M.L., J.M.G., A.G.S., P.E.M.P., and L.S.Z. analyzed data; E.S.C. wrote the first draft of the paper; E.S.C. and L.S.Z. edited the paper; E.S.C. wrote the paper; A.C.H., S.A.T., and M.D. contributed unpublished reagents/analytic tools.

This work was supported by Department of Veteran's Affairs (salary for E.S.C.) and the National Institutes of Health Grant K08-MH104281 and R01-MH116883 to E.S.C., and Grants R01-MH0945 and R21-MH098177 to L.S.Z. We thank the L.S.Z. and E.S.C. laboratory members for careful review (especially Marta Soden); Hirofumi Fujita and Richard Palmiter for scientific discussion; and Scott Ng-Evans for help with programming operant chambers.

The authors declare no competing financial interests.

Correspondence should be addressed to Erik S. Carlson at esc1@uw.edu.

https://doi.org/10.1523/JNEUROSCI.2406-20.2021

Copyright $\odot 2021$ the authors
}

\section{Introduction}

Several recent reports indicate that the cerebellum processes nonmotor signals related to fear (Sacchetti et al., 2002, 2004, 2007; Scelfo et al., 2008) and reward (Mittleman et al., 2008; Thoma et al., 2008; Rogers et al., 2011; Wagner et al., 2017; Carta et al., 2019; Heffley and Hull, 2019; Kostadinov et al., 2019; Tsutsumi et al., 2019), which supports the hypothesis that cerebellum participates in nonmotor functions. The catecholamines dopamine (DA) and norepinephrine (NE) are neuromodulatory neurotransmitters well known for processing such salient stimuli and facilitating learning mechanisms related to approach, 
avoidance, and cognitive behaviors (Schultz, 2013; Aston-Jones and Waterhouse, 2016). Dopaminergic (Ikai et al., 1992; Melchitzky and Lewis, 2000) and noradrenergic (Hokfelt and Fuxe, 1969; Olson and Fuxe, 1971; Landis and Bloom, 1975; Landis et al., 1975; Loughlin et al., 1986a,b; Nelson et al., 1997) innervation of the cerebellum has been documented in several species, and NE modulates classical cerebellar functions (Watson and McElligott, 1983, 1984; Paredes et al., 2009). Notably, NE regulates associative synaptic plasticity between climbing fibers and Purkinje cells (PCs) (Carey and Regehr, 2009), and PCs release DA in an autocrine manner from dendrites to regulate PC excitability (Y. S. Kim et al., 2009).

We previously found that DA D1 receptor-positive $\left(\mathrm{D} 1 \mathrm{R}^{+}\right)$ neurons residing in a specific subregion of the lateral cerebellar nucleus (LCN) in mice project to several brainstem, midbrain, and thalamic nuclei associated with cognitive functions (Locke et al., 2018). $\mathrm{D} \mathrm{R}^{+} \mathrm{LCN}$ neurons are necessary for spatial navigation memory, social recognition memory, temporally dependent response inhibition, and maintenance of working memory in mice (Locke et al., 2018). Pharmacological blockade of LCN D1Rs results in attenuation of neuronal firing patterns in PFC, and impaired interval timing performance associated with these patterns (Heskje et al., 2020). TH expression by PCs is required for performance in many cognitive domains (Locke et al., 2020). However, very little is known about whether the LCN receives catecholaminergic innervation, or what the role of catecholaminergic innervation of the $\mathrm{LCN}$ is in facilitating learning or modulating these cognitive functions in the context of cerebellar function.

We hypothesized that the LCN could be targeted to interrogate catecholamine-dependent cognitive functions of the cerebellum. In the context of cerebellar catecholamines, the LCN is of great interest. Catecholamines modulate classical cerebellar associative eyeblink conditioning in the interposed cerebellar nucleus (Cartford et al., 2004). In humans, the dentate nucleus of the cerebellum (analog of rodent LCN) shows activation during cognitive performance, and has divisions with differential activations during cognitive and motor tasks (S. G. Kim et al., 1994; Dum and Strick, 2003; Kuper et al., 2011; Tellmann et al., 2015). Furthermore, cerebellar nuclei $(\mathrm{CN})$ contain output neurons with axons that bifurcate with projections to both thalamus and to cerebellar cortex (CCtx) (Houck and Person, 2015), process efference copy signals from cerebral cortex (Houck and Person, 2015) and regulate associative learning in CCtx (Gao et al., 2016). Notably, the LCN sends projections to regions of CCtx implicated in cognitive function (Locke et al., 2018). Here, we confirm the presence, quantify the amount of $\mathrm{TH}^{+}$fibers in the LCN (relative to all other cerebellar regions), and map their origins in mice. Using high-pressure liquid chromatography (HPLC), we found that NE is the major catecholamine present in LCN. Advanced mapping techniques revealed extrinsic (locus coeruleus [LC]) and intrinsic (subpopulation of PCs) sources of LCN catecholamines. Using fast scan cyclic voltammetry (FSCV), we found that LC stimulation results in LCN catecholamine release. Selective deletion of Th from all fibers innervating the LCN impaired sensorimotor integration, associative fear learning, response inhibition, and learning of a working memory task. Finally, we found that selective inhibition of excitatory LCN output neurons with inhibitory designer receptor exclusively activated by designer drugs (DREADDs) led to facilitation of learning on the working memory task impaired in LCN-Th-cKO mice. These results suggest that catecholamine-facilitated learning mechanisms in the LCN are necessary for certain cognitive functions.

\section{Materials and Methods}

Mice. The University of Washington Institutional Animal Care and Use Committee approved all experimental protocols. Heterozygous mice with insertion of Cre recombinase at the Dbh locus (Dbh-IRES-Cre mice have been previously described) (Roman et al., 2016) were bred and used in this study. Heterozygous mice with insertion of Cre recombinase at the DAT locus Slc6a3 ${ }^{\text {Crel+ }}$ (Zhuang et al., 2005), the Slc17a6 locus (Vglut2) (Vong et al., 2011), and $T h^{\text {lox/lox }}$ (homozygous) mice (Jackson et al., 2012) were previously described, bred, and used in this study. For quantification of $\mathrm{Dbh}^{+}$cells in the LC, Dbh-IRES-Cre mice were crossed with a TdTomato line expressing Tomato in a Cre-dependent manner (Madisen et al., 2010). Only male mice were used for behavioral experiments in this study. Mice were given ad libitum food and water, except during food restriction to $85 \%$ of their ad libitum body weight, while housed on a 12:12 light:dark cycle. Mice were genotyped by PCR.

Quantification of catecholamines and their metabolites with HPLC. Brains from mice euthanized with Beuthanasia $(250 \mathrm{mg} / \mathrm{kg})$ were removed and placed on an ice-cold metal plate; 1-mm-thick slices were taken through the frontal cortex, striatum, and cerebellum with a mouse brain matrix (Activational Systems), and 1-mm-diameter tissue punches were taken from LCN, medial nucleus (MN) and posterior vermis, pooled from 6 to 9 individual animals and placed into $1.5 \mathrm{ml}$ microcentrifuge tubes, and quickly frozen in liquid nitrogen. Samples were stored at $-8^{\circ} \mathrm{C}$ until they were shipped on dry ice to Neurochemistry Core Lab (Vanderbilt University Center for Molecular Neuroscience Research) for analysis. The brain sections were then homogenized, using a tissue dismembrator, in 100-750 $\mu \mathrm{l}$ of $0.1 \mathrm{M} \mathrm{TCA}$, which contains $10^{-2} \mathrm{M}$ sodium acetate, $10^{-4} \mathrm{M}$ EDTA, and $10.5 \%$ methanol, $\mathrm{pH} 3.8$; $10 \mu \mathrm{l}$ of homogenate was used for the protein assay. Then samples were spun in a microcentrifuge at $10,000 \times g$ for $20 \mathrm{~min}$. The supernatant was then removed for biogenic monoamines analysis.

Biogenic amine analysis using HPLC-electrochemical detection. Biogenic amine concentrations were determined using a Thermo Fisher Scientific Dionex Ultimate 3000 ECD-3000RS module with dual electrochemical detection capabilities with 2 -coulometric flow cells and an Omni coulometric flow cell operated at $32^{\circ} \mathrm{C} ; 20 \mu \mathrm{l}$ samples of the supernatant were injected using a Thermo Fisher Scientific Ultimate 3000 WPS-3000TBRS Thermostatted Biocompatible Rapid Separation SplitLoop Autosampler. Vanquish Horizon UHPLC onto a Phenomenex Kintex C18 HPLC column $(100 \times 3.0 \mathrm{~mm}, 2.6 \mu \mathrm{m})$. Biogenic amines were eluted with a mobile phase consisting of $89.5 \% 0.1 \mathrm{M} \mathrm{TCA}, 10^{-2}$ $\mathrm{M}$ sodium acetate, $10^{-4} \mathrm{M}$ EDTA, and $10.5 \%$ methanol, $\mathrm{pH} 3.8$. Solvent was delivered at $0.6 \mathrm{ml} / \mathrm{min}$ using a Waters 515 HPLC pump. Using this HPLC solvent, the following biogenic amines eluted in the following order: noradrenaline, adrenaline, 3,4-dihydroxyphenylacetic acid (DOPAC), DA, 5-hydroxyindoleacetic acid, homovanillic acid (HVA), 5HT, and 3-methoxytyramine (3-MT) over $8 \mathrm{~min}$. Data acquisition was managed by Chromeleon 7.2 software. Isoproterenol $(5 \mathrm{ng} / \mathrm{ml})$ was included in the homogenization buffer for use as an internal standard to quantify the biogenic amines.

Protein assay. Protein concentration was determined by BCA Protein Assay Kit (Thermo Fisher Scientific); $10 \mu \mathrm{l}$ tissue homogenate was distributed into 96-well plate, and $200 \mu$ l of mixed BCA reagent $(25$ $\mathrm{ml}$ of Protein Reagent A was mixed with $500 \mu \mathrm{l}$ of Protein Reagent B) was added. The plate was incubated at room temperature for $2 \mathrm{~h}$ for the color development. A BSA standard curve was run at the same time. Absorbance was measured by the plate reader (POLARstar Omega), purchased from the BMG LABTECH. The electrochemical detector was an Ultimate 3000 ECD-3000RS module with dual ECD capabilities with 2coulometric flow cells and an Omni coulometric flow cell.

Immunohistochemistry. For fluorescent immunostaining in mice, $40 \mu \mathrm{m}$ frozen sections were collected after the animals were transcardially perfused with PBS followed by $4 \%$ PFA. Brains were dissected, postfixed in 4\% PFA for 12-24 h, and placed in 30\% sucrose for $48 \mathrm{~h}$. Brains were then embedded in Tissue Freezing media and stored in a $80^{\circ} \mathrm{C}$ freezer until sectioning. The following primary antibodies were used: GFP, mouse monoclonal, 1:1000 (Invitrogen); (Rb anti-GFP, Takara Clontech, 1:1000), DsRed mouse monoclonal, 1:1000 (Applied Biological Materials); TH rat monoclonal, 1:200 (Sigma Millipore; all 
fluorescent secondary antibodies were 1:200; Jackson ImmunoResearch Laboratories).

For serial section analysis of TH staining throughout the cerebellum, brains were sent to NeuroScience Associates and were examined, treated overnight with $20 \%$ glycerol and $2 \%$ DMSO to prevent freeze artifacts. Embedding, sectioning, and staining were performed at NeuroScience Associates. The specimens were then embedded in a gelatin matrix using MultiBrain/MultiCord Technology (NeuroScience Associates). The blocks were rapidly frozen, after curing by immersion in 2-methylbutane chilled with crushed dry ice and mounted on a freezing stage of an AO 860 sliding microtome. The MultiBrain/MultiCord blocks were sectioned in coronally (35 $\mu \mathrm{m}$ sections) setting on the microtome. All sections were cut through the entire length of the specimen segment and collected sequentially into series of 24 containers. All containers contained Antigen Preserve solution (50\% PBS, pH 7.0, 50\% ethylene glycol, $1 \%$ polyvinyl pyrrolidone); no sections were discarded. Every sixth section was taken for immunohistochemistry. Serial sections were taken from 20 male mice. Mice were $\sim 3$ months of age ( 10 mice) and $\sim 6$ months of age (10 mice).

For TH immunohistochemistry in serial cerebellar sections, freefloating sections were stained with a rabbit anti-TH primary antibody (1:1000, Pel Freez). All incubation solutions from the primary antibody onward use TBS with Triton X-100 as the vehicle; all rinses are with TBS. After a hydrogen peroxide treatment, the sections were immunostained with primary antibody, overnight at room temperature. Vehicle solutions contained Triton X-100 for permeabilization. Following rinses, a biotinylated secondary antibody (anti IgG of host animal in which the primary antibody was produced) was applied. After further rinses, Vector Lab's ABC solution (avidin-biotin-HRP complex; details in instruction for VECTASTAIN Elite ABC, Vector) was applied. The sections were again rinsed, then treated with $\mathrm{DAB}$ and hydrogen peroxide to create a visible reaction product. Following further rinses, the sections were mounted on gelatin-coated glass slides and air dried. The slides were dehydrated in alcohols, cleared in xylene, and coverslipped.

For subregional analysis of LC, cells were counted in coronal sections from 5 brains and $20 \times$ magnification with ImageJ software measuring tool (National Institutes of Health) at a defined ROI centered on the LC. After every $40 \mu \mathrm{m}$ coronal section was collected sequentially into PBS, sections were washed $2 \times 10 \mathrm{~min}$ in PBS and blocked for 2-3 h at room temperature in $3 \%$ normal donkey serum in TBST. Primary antibody was diluted in $3 \%$ normal donkey serum in TBST and incubated overnight at $4^{\circ} \mathrm{C}$. After $3 \times 10 \mathrm{~min}$ washes in TBS, secondary antibodies were applied overnight at $4^{\circ} \mathrm{C}$ (anti-rabbit AlexaFluor-488, 1:200, Jackson ImmunoResearch Laboratories), followed by $3 \times 10 \mathrm{~min}$ washes in TBS. Sections were additionally stained with DAPI. Regions with GFP positivity were manually counted from every $40 \mu \mathrm{m}$ section through the entire brain in each of 4 animals per genotype. All images were acquired using a $10 \times$ objective on a Keyence slide microscope or a Nikon Eclipse E600 upright microscope, and processed using National Institutes of Health ImageJ software.

Image analysis of TH staining in serial cerebellar sections. Slides with $\mathrm{TH}$-stained cerebellar sections were placed and scanned on an Aperio $\mathrm{AT}^{2}$ slide scanner (Leica Biosystems). Image analysis protocols were developed for digital quantification of TH using Visiopharm software. $\mathrm{TH}$ quantification was performed on the following brain nuclei: $\mathrm{CN}$ (lateral, medial, and interposed), inferior olive (IO), reticularis tegmenti pontis nuclei (RtTg), pontine nucleus, LC, medial vestibular nuclei $(\mathrm{MVN})$, lateral reticular nucleus (LRN), external cuneate nucleus. TH quantification was also performed on both the molecular and granular layers of the lobules and hemispheres of the cerebellum. Analyzing nuclei involved the manual selection of the ROIs in 15-20 representative images. Visiopharm deep learning APP analyzed the manually traced ROI and then machine-learning was used to outline the ROI(s) in remaining images. All images were then reviewed for ROI selection accuracy. The ROIs for cerebellar lobules and hemispheres were all manually traced. The selected ROI(s) were then subjected to computer assisted analysis to recognize and quantify positive DAB-TH. Specifically, each region came from the following datasets: IO: 37 images were analyzed from 19 animals. RtTg: 46 images were analyzed from 20 animals. Basilar pontine nuclei: 42 images were analyzed from 20 animals. Cerebellar hemispheres: 120 images were analyzed from 20 animals. Vermal lobules: 120 images were analyzed from 20 animals. CN: 80 images were analyzed from 20 animals. MVN: 77 images were analyzed from 20 animals. External cuneate nucleus: 54 images were analyzed from 20 animals. LRN: 15 images were analyzed from 15 animals. The DAB intensity threshold within Visiopharm DAB APP was used to determine positivity versus negativity of the TH expression.

Output variables measured were ROI area, TH area inside the ROI, and average DAB intensity of TH expressed (Fristrup et al., 2013). The average $\mathrm{DAB}$ intensity is subtracted from 255 to associate high values with a high staining intensity, which is more intuitive. Positive area fraction for each ROI was calculated (TH area/ROI area). The final TH expression is calculated by multiplying the intensity and the positive area fraction (Fristrup et al., 2013).

Viral vectors. Shuttle plasmids AAV-FLEX-Hm4Di-YFP, AAVFLEX-GFP, AAV1-DIO-Synaptophysin-GFP, AAV2retro-DIO-GFP, CAV2-Cre, and CAV2-zsGreen were produced in house (titer $\sim 1 \times$ $10^{12} / \mathrm{ml}$ ), as described previously (Gore et al., 2013). The promoter/ enhancer for Synapto-GFP virus is EFlalpha, and all other viruses have the CAG promoter/enhancer. Serotype 1 was used for all viruses. Packaging plasmid: pDG1.

Viral injections, experimental groups, and verification of $L C N T H$ $K O$. KO of $\mathrm{TH}$ in catecholamine-positive projections to LCN was achieved by stereotaxically guided injection (bilateral) of the retrograde CAV2-Cre $\left(0.5 \mu\right.$ l, titer $\sim 1 \times 10^{12} / \mathrm{ml}$ ) to the LCN (LCN coordinates: $y=-6.3 \mathrm{~mm}, x= \pm 2.4 \mathrm{~mm}, z=-3.3 \mathrm{~mm}$ down to $-3.8 \mathrm{~mm})$ in $T h^{\text {lox }} /$ ox mice. For littermate controls, stereotaxic viral injections in mice, $0.5 \mu \mathrm{l}$ of CAV2-zsGreen (titer $\sim 1 \times 10^{12} / \mathrm{ml}$ ) was bilaterally injected into the LCN. After surgery, mice recovered for 3 weeks before behavioral testing. Viral expression was confirmed by immunohistochemistry with the TH antibody detecting TH. Viral "hits" were verified by Western blot of LCN tissue isolated by hole punch of a section of cerebellum or TH staining in coronal sections after termination of the experiment. For Westerns, we stained with 1:10,000 Millipore Rabbit anti-TH antibody AB152, quantified after normalization to Millipore mouse anti- $\beta$-actin antibody stain, AB1501, concentration =1:8000.

Expression of the inhibitory DREADD in LCN of Vglut2-Cre mice was achieved by injecting $0.5 \mu \mathrm{l}$ of AAV-FLEX-Hm4Di-YFP (titer $\sim 1 \times$ $10^{12} / \mathrm{ml}$ ) or control AAV-FLEX-GFP (titer $\sim 1 \times 10^{12} / \mathrm{ml}$ ) was bilaterally injected into the dentate (or lateral) nucleus of the cerebellum $(x=$ $\pm 2.4, y=-6.3, z=-3.3 \mathrm{~mm}$ down to $-3.8 \mathrm{~mm}$ ). After surgery, mice recovered for 3 weeks before behavioral testing. Viral expression was confirmed by immunohistochemistry with the GFP antibody detecting GFP or YFP. Stereotaxic injection was performed as described previously (Gore et al., 2013).

Nonsurvival voltammetry surgeries. Mice 3-5 months of age were anesthetized with $1.5 \mathrm{~g} / \mathrm{kg}$ urethane (intraperitoneal), and holes were drilled over the LCN and LC. A carbon fiber electrode was implanted in the LCN (coordinates relative to bregma: $y=-6.3 \mathrm{~mm}, x= \pm 2.4 \mathrm{~mm}$, $z=-3.3 \mathrm{~mm}$ down to $-3.8 \mathrm{~mm}$ ) along with an $\mathrm{Ag} / \mathrm{AgCl}$ reference electrode were implanted with a stereotaxic frame. Stimulating electrodes were then placed in the ipsilateral LC.

Voltammetry recording sessions. A triangle waveform was applied to the carbon fiber, which was ramped from -0.4 to $1.3 \mathrm{~V}$ and back (vs $\mathrm{Ag} / \mathrm{AgCl}$ ) at a rate of $400 \mathrm{~V} / \mathrm{s}$ and a frequency of $10 \mathrm{~Hz}$ (held at $-0.4 \mathrm{~V}$ between scans), as previously described (Wanat et al., 2013). Catecholamine release was evoked by electrical stimulation ( 60 pulses delivered at $60 \mathrm{~Hz}, 250 \mathrm{~mA}$ ) via a bipolar stimulating electrode that was incrementally lowered into the LC, and stimulations were performed every $5 \mathrm{~min}$.

Pharmacology experiments. Stimulations were performed every $5 \mathrm{~min}$ at 60 pulses, $60 \mathrm{~Hz}$, and $250 \mu \mathrm{A}$ until a stable baseline was reached $(<10 \%$ deviation from the mean peak response of catecholamine between four stimulations, over $\sim 20 \mathrm{~min}$ ), and after maximum catecholamine release was achieved. After acquiring stable catecholamine transients, we applied intraperitoneal injections of either the DA D2 receptor (D2R) antagonist eticlopride (Tocris Bioscience; concentration $=0.5 \mathrm{mg} / \mathrm{kg}$ ), or the adrenergic alpha-2 receptor antagonist idazoxan (Tocris Bioscience; concentration= $1 \mathrm{mg} / \mathrm{kg}$ ) and continued recording every $5 \mathrm{~min}$ for $60 \mathrm{~min}$. 
Table 1. Measurement of catecholamines and catecholamine metabolites in different cerebellar regions in mouse ${ }^{a}$

\begin{tabular}{|c|c|c|c|c|c|c|}
\hline Region & $\mathrm{NE}$ & Epinephrine & DOPAC & DA & HVA & 3-MT \\
\hline LCN & $4.74 \pm 0.24$ & $0.00 \pm 0$ & $0.15^{b}(1 / 8)$ & $0.18 \pm 0.01^{b}(3 / 8)$ & $0.24 \pm 0.03^{b}(5 / 8)$ & $0.00 \pm 0$ \\
\hline Medial CN & $6.83 \pm 0.51$ & $0.00 \pm 0$ & $0.17^{b}(1 / 8)$ & $0.21^{b}(1 / 8)$ & $0.31 \pm 0.03^{b}(6 / 8)$ & $0.00 \pm 0$ \\
\hline Posterior vermis & $6.55 \pm 0.64$ & $0.00 \pm 0$ & $0.00 \pm 0$ & $0.47 \pm 0.06^{b}(2 / 7)$ & $0.41 \pm 0.02^{b}(3 / 7)$ & $0.00 \pm 0$ \\
\hline Frontal cortex & $9.66 \pm 0.84$ & $0.00 \pm 0$ & $0.00 \pm 0$ & $2.13 \pm 0.71$ & $3.21 \pm 0.28$ & $0.00 \pm 0$ \\
\hline Striatum & $10.03 \pm 0.77$ & $0.00 \pm 0$ & $13.74 \pm 2.06$ & $77.92 \pm 6.66$ & $11.72 \pm 0.88$ & $4.44 \pm 0.37$ \\
\hline
\end{tabular}

${ }^{a} \mathrm{~N}=6-9$ pooled samples in each group. Data are mean \pm SEM (ng/mg protein).

${ }^{b}$ Not measured in each sample (number of samples with measurable amount/total sample), and only samples with measurable amounts are averaged.
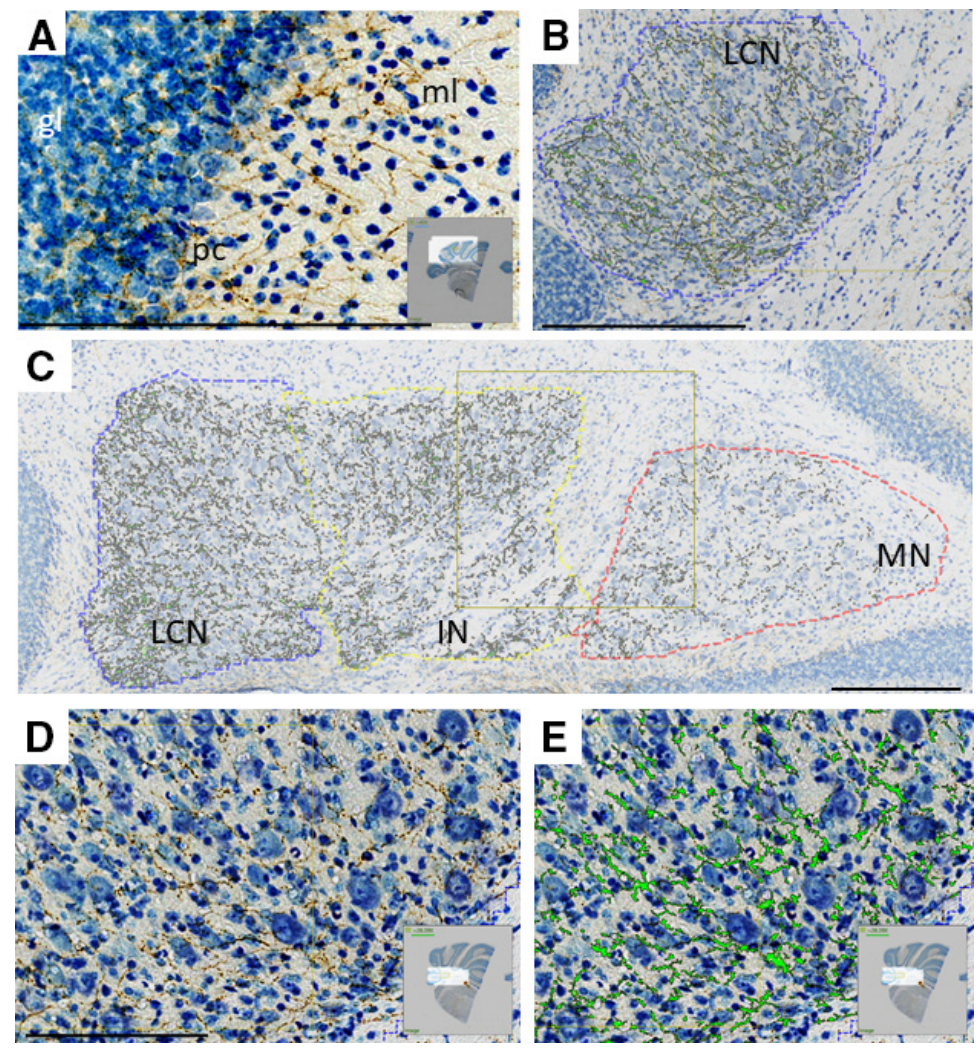

Figure 1. Immunohistochemistry reveals staining for TH-positive fibers (brown represents DAB, anti-TH antibody; blue represents thionine/Nissl stain), which innervate multiple regions of cerebellum in coronal sections. Staining was positive in each of 20 animals. A, Microscope image of CCtx with staining for TH. ml, Molecular layer; pc, PC layer; gl, granule cell layer. $\boldsymbol{B}$, Representative image of $\mathrm{TH}^{+}$staining in $\mathrm{LCN}$, with green overlay of pixels determined to have TH positivity by analysis software. C, Representative image of $\mathrm{TH}^{+}$staining in $\mathrm{CN}(\mathrm{LCN}, \mathrm{IN}$, and MN) analyzed in this study with green overlay of pixels determined to have TH positivity by analysis software. $\boldsymbol{D}$, Higher magnification of image in $\boldsymbol{B}$, with $\mathrm{TH}^{+}$staining (brown) in the $\mathrm{LCN}$. $\boldsymbol{E}$, Higher magnification of image in $\boldsymbol{F}$, with $\mathrm{TH}^{+}$staining overlain with green pixels determined to have TH positivity by analysis software in the LCN. Scale bars: $\boldsymbol{A}-\boldsymbol{E}, 250 \mu \mathrm{m} . \boldsymbol{A}, \boldsymbol{D}, \boldsymbol{E}$, Insets, Origin of images from complete coronal section.

Mouse behavioral experiments. Male animals were injected at 10 weeks of age and were run on our behavioral pipeline in a fixed temporal order starting at age of $90 \mathrm{~d}$. The pipeline for this study consisted of rotarod ( $4 \mathrm{~d})$, startle curve measurement, and prepulse inhibition of the acoustic startle reflex (PPI) $(1 \mathrm{~d})$, open field test $(1 \mathrm{~d})$, fixed ratio 1 (FR1) lever training (5d), delayed alternation and reversal (DA) (10d), and fear conditioning ( $3 \mathrm{~d}$ ), for a total of $\sim 1$ month ( $26 \mathrm{~d}$ ) of behavioral assays. Additional male animals were generated to test on the same pipeline, but instead of delayed alternation, they were run on the differential reinforcement of low-rate responses (delayed reinforcement of low rates [DRL] task) for 5 weeks, for a total of $\sim 6$ weeks ( $48 \mathrm{~d}$ ) of behavioral assays. Additional male animals were generated to test performance on the Barnes Maze (5d).

Vglut2-Cre mice expressing either AAV-FLEX-Hm4Di-YFP or control AAV-FLEX-GFP in LCN were given $0.1 \mathrm{ml} / 10 \mathrm{~g}$ body weight of $0.1 \mathrm{mg} / \mathrm{ml}$ of clozapine- $n$-oxide $(\mathrm{CNO})$ was applied via intraperitoneal injection to achieve a final dose of $1 \mathrm{mg} / \mathrm{kg}$ in each mouse, $45 \mathrm{~min}$ before each training trial or behavioral task we measured. Vglut2-Cre mice expressing either AAV-FLEX-Hm4Di-YFP or control AAVFLEX-GFP in LCN were run on a similar behavioral pipeline as above, but limited to rotarod ( $4 \mathrm{~d})$, startle curve measurement and prepulse inhibition of the acoustic startle reflex (PPI) (1d), open field test (1 d), FR1 lever training (4d), delayed alternation and reversal (DA) (19d), for a total of $\sim 1$ month (25 d) of behavioral assays.

Fear conditioning. To test attention to salient sensory stimuli, we used a discriminative delayed cued fear conditioning paradigm in which the subject was exposed to an auditory cue (a specific tone, conditioned stimulus $\left[\mathrm{CS}^{+}\right]$) predictive of a lowamplitude shock $(0.3 \mathrm{~mA}, 0.5 \mathrm{~s})$ and an auditory cue that was not predictive of the shock $\left(\mathrm{CS}^{-}\right)$. This test required the subject to discriminate between cues in the context of a predicted shock; learning was measured by the amount of freezing after playing $\mathrm{CS}^{+}$or $\mathrm{CS}^{-}$during the probe trial. This test typically does not result in generalized fear, and likely requires more attention than tests with higher-amplitude shocks (Sanford et al., 2017). Conditioning and test sessions were performed in a standard operant chamber (Med Associates) equipped with a tone generator and house light. Baseline responses to two distinct auditory stimuli $(10 \mathrm{kHz}$ pulsatile tone and a $20 \mathrm{kHz}$ continuous tone, each $10 \mathrm{~s}$ in duration) were established by three interleaved presentations of the cues. Mice were then conditioned to $\mathrm{CS}^{+}$presentations (10 s auditory cue) coterminating with the unconditioned stimulus and $\mathrm{CS}^{-}$presentations (distinct $10 \mathrm{~s}$ auditory cue that did not coterminate with an unconditioned stimulus) on 2 consecutive days. Daily sessions that were repeated over 2 consecutive days consisted of 10 presentations of the $\mathrm{CS}^{+}$coterminating with a $0.3 \mathrm{~mA}$ foot shock alternating pseudo-randomly with 10 presentations of the $\mathrm{CS}^{-}$on a $60 \mathrm{~s}$ intertrial interval. Assignment of the tones as the $\mathrm{CS}^{+}$and $\mathrm{CS}^{-}$was counterbalanced across groups. Twenty-four hours after conditioning, on 2 consecutive days, mice were probed for discriminative threat responding by monitoring freezing in response to three interleaved presentations of the $\mathrm{CS}^{+}$and $\mathrm{CS}^{-}$, which were delivered at a $60 \mathrm{~s}$ interval in the absence of the unconditioned stimulus. Test sessions were conducted in a different context from the conditioning, consisting of solid white walls and flat white floor with acetic acid olfactory cues. All sessions were analyzed with Ethovision (Noldus) tracking software after video recording.

Prepulse inhibition of the acoustic startle reflex. Prepulse inhibition of the acoustic startle reflex was performed in sound-attenuated chambers (San Diego Instruments). To measure prepulse inhibition, mice were given 5 trials of $120 \mathrm{~dB}$ startle pulse alone, followed by 50 trials, which pseudorandomly alternated between $120 \mathrm{~dB}$ pulse alone, one of three prepulse intensities, or null (no startle), with a variable intertrial interval. Prepulse trials consist of $20 \mathrm{~ms}$ duration prepulse at the indicated intensity occurring $100 \mathrm{~ms}$ before the $40 \mathrm{~ms} 120 \mathrm{~dB}$ startle pulse on one day. 

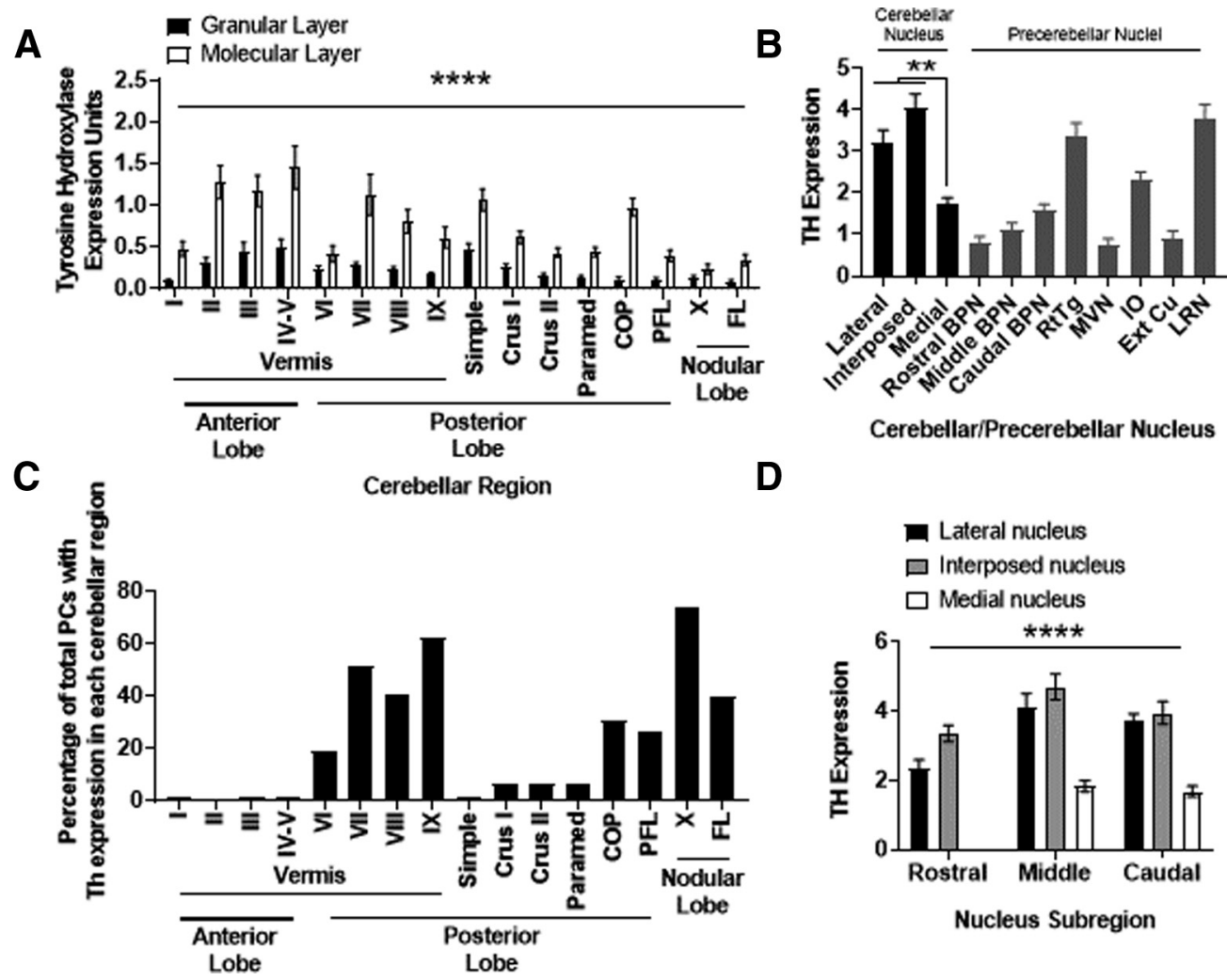

Figure 2. Quantification of regional TH expression in cerebellar and precerebellar structures. $A$, Relative TH expression in each vermal lobule, and hemispheric region, by cortical layer. Differences were observed between groups for the effect of cerebellar region $\left(F_{(15,608)}=11.81, p<0.0001\right)$, cortical layer $\left(F_{(1,608)}=192, p<0.0001\right)$, and interaction $\left(F_{(15,608)}=3.76\right.$, $* p<0.0001$ ) between these two factors on two-way ANOVA. $N=20$ brains. Error bars indicate SEM. $B$, Relative TH expression in each cerebellar nucleus, and selected pre-CN. Differences were observed between groups $(F=27.76, p<0.0001)$ on one-way ANOVA. On post hoc analysis, no difference was seen in TH expression between LCN and IN. Both LCN and IN had significantly greater $(* p<0.01)$ TH expression than MN. 10: $N=19$ animals. RtTg: $N=20$ animals. Basilar pontine nuclei (BPN): $N=20$ animals. CN (LCN, IN, MN): $N=20$ animals. MVN: $N=20$ animals. External cuneate nucleus (Ext $\mathrm{Cu}$ ): $N=20$ animals. LRN: $N=15$ animals. Error bars indicate SEM. $C$, To aid in the analysis of data graphed in $\boldsymbol{A}$, we graphed data (expressed as the percentage of total PCs with Th expression in each cerebellar region) we developed from regional PC Th mRNA expression, as we reported previously (Locke et al., 2020). D, Relative TH expression in rostrocaudal subregions of each cerebellar nucleus. Differences were observed between groups for the effect of cerebellar nucleus $\left(F_{(2,171)}=106.4, * p<0.0001\right)$, rostrocaudal expression $\left(F_{(2,171)}=35.16, p<0.0001\right)$, but not interaction $\left(F_{(4,171)}=1.28, p=0.28\right)$ between these two factors on two-way ANOVA. Post hoc analysis revealed significant differences between rostral LCN and middle LCN $(p<0.0001)$, rostral LCN and caudal LCN $(p<0.004)$, rostral IN and middle IN $(p<0.007)$, but not rostral IN and caudal IN $(p=0.76)$, and no differences were seen in TH expression in MN sections on the rostrocaudal axis. $N=20$ animals. Error bars indicate SEM. In each panel, asterisk indicates which comparison is noted by the significance bar. $* * p<0.01 ; * * * * p<0.0001$.

Gait analysis. A mouse's hindfeet and forefeet were dipped in nontoxic, acrylic paint (red and green, respectively) (Crayola), and then it could walk up a slightly inclined, 1-m-long platform into a dark box. Print dimensions (stride lengths, widths) were then measured for analysis.

Rotarod. A mouse was placed on a rotating rod apparatus (Columbus Instruments) in a neutral position on a cylinder that was stationary. The rotarod was then switched on at a speed of $4 \mathrm{rpm}$ with increasing speed (4-40 rpm over $5 \mathrm{~min}$ ), and the latency to fall was recorded by the apparatus and watched by an observer. This procedure required three sessions a day for $5 \mathrm{~d}$ for each animal. Mice that hung on to the cylinder were noted by the observer at what time they began to hang and scored as a fall at that time.

Barnes Maze. The Barnes Maze protocol was performed as previously described (Locke et al., 2018), with no alterations. The maze is an elevated circular platform with 20 equally spaced holes along the perimeter. Animals receive a bright light reinforcement to escape from the open maze surface to a small, dark recessed goal box under the target hole located under the platform. Visual cues (with different colors and shapes) surround the maze and were not moved during the experiment. For adaptation, acquisition, and probe trials, each mouse is started in an upside-down cup in the center of the maze, which is removed at the start of the trial. During acquisition trials, each mouse explored the maze for $3 \mathrm{~min}$. During this time interval, percent time in the target quadrant and distance traveled were measured. Acquisition trials end after $3 \mathrm{~min}$ have elapsed or when the mouse enters the goal box. Each mouse had four trials per day for $4 \mathrm{~d}$ with an intertrial interval of $15 \mathrm{~min}$. A probe trial was conducted $24 \mathrm{~h}$ after the last training day. For probe trials, the goal box under the target hole was removed. During the $90 \mathrm{~s}$ probe trial, nose pokes into the target hole, holes in the target quadrant, and latency to reach the goal were measured. Holes in the target quadrant were defined by the target hole plus the 2 holes on either side of the target hole. Data were acquired and analyzed using Ethovision software (Noldus).

Instrumental conditioning. Conditioning was performed in soundattenuated chambers (Med Associates). To test simple reward learning and motivation, we used an established appetitive simple instrumental conditioning task (Gore and Zweifel, 2013). Mice were calorie restricted to $85 \%$ of body weight and were monitored for learning in an FR1 reward schedule in which one lever press results in delivery of one sucrose pellet. Four days of instrumental conditioning were performed in male mice. The session continued until 50 trials were completed or $2 \mathrm{~h}$ had elapsed.

Differential reinforcement of low rate responding. To gauge impulsivity, we used the operant task, differential reinforcement of low-rate responding (DRL) paradigm as previously described (Nautiyal et al., 2015), with minor alterations. Mice began training on the DRL-10 paradigm the day after they completed $4 \mathrm{~d}$ of lever training on an FR1 schedule. In the DRL-10, responses before $10 \mathrm{~s}$ have elapsed after the last press resulted in a reset, while presses that are preceded by at least $10 \mathrm{~s}$ were rewarded with one sucrose pellet. The subject must learn to inhibit lever press responses for the duration to receive the reward. Mice were trained daily for 5 weeks at the $10 \mathrm{~s}$ interval. All sessions lasted $1 \mathrm{~h}$, and no limit 
A
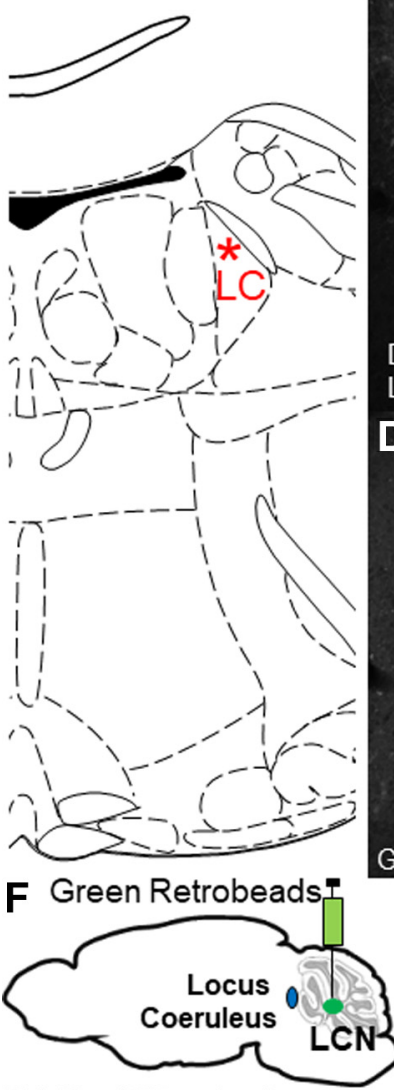

Dbh-iCre::TdTomato mice

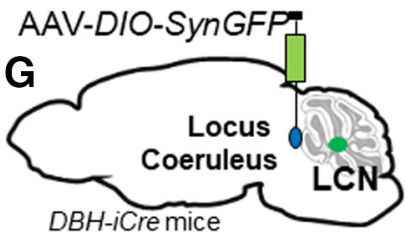

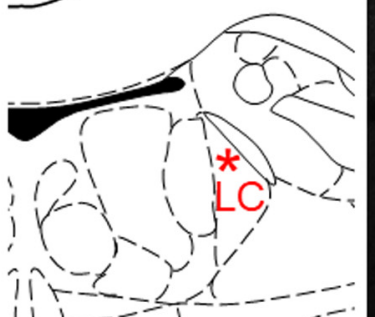

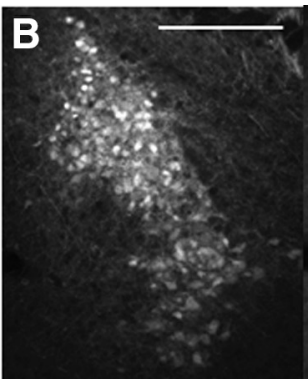

DBH-cre; TdTomato Locus Coeruleus

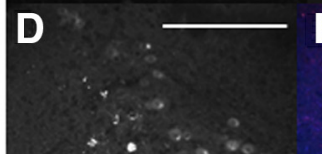

\section{C}

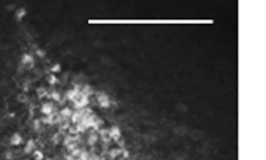

levers were retracted, and no other cues (e.g., house light or sound) were associated with the delay. The levers were then presented after the delay, and the mouse had to learn to press the opposite lever than was originally pressed for the reward of one sucrose pellet; then, there was a $20 \mathrm{~s}$ intertrial interval, and then the process is repeated. Learning was assessed as a fraction of correct alternations out of each opportunity, and the number of pellets delivered. For the reversal, instead of getting a food pellet reward for pressing the opposite lever after the delay, the subject had to learn to press the same lever after the delay to get a food pellet reward. Mice were trained daily for several days on each delay interval. For Vglut2-Cre mice expressing either AAV-FLEX-Hm4Di-YFP or control AAV-FLEX-GFP in the LCN, CNO was injected $45 \mathrm{~min}$ before training on each day. Experimental and control mice were compared using a two-way repeated-measures ANOVA (viral group $\times$ day of training).

Experimental design and statistical analyses. Data were analyzed using Excel (Microsoft) and Prism software (GraphPad), using ANOVA (with repeated measures and appropriate post hoc analyses when indicated), or Student's $t$ test as indicated. An $\alpha$ of $p<0.05$ was considered significant. Details of specific statistical analyses are found in the figure legends, except where noted in Results. No randomization was used to assign experimental groups, but groups were assigned without bias. Virus-injected animals in which the target was missed were excluded ( 3 total animals). One animal was removed from the delayed alternation analysis because of failure of lever apparatus. Behavioral data were acquired and analyzed in an unbiased way by an investigator without knowledge of the experimental groups.

\section{Results}

Quantification of catecholamines and metabolites in selected cerebellar regions

Previous reports in rodents indicate higher levels of catecholamines in the $\mathrm{CN}$ than CCtx, or even hippocampus (Laatikainen et al., 2013), and levels similar to those in areas of frontal cortex (Versteeg et al., 1976). To confirm and extend previous measurements of brain catecholamines in rats, we quantified NE, DA, and their metabolites using HPLC in specific cerebellar regions isolated from mice (Table 1). We hypothesized that DA, NE, and their metabolites would be present in the LCN, as they have been previously observed in all of the vermal lobules, hemispheres, and each $\mathrm{CN}$ in rodents (Bloom et al., 1971; Versteeg et al., 1976; R. Freedman, 1977; R. Freedman et al., 1977; Panagopoulos et al., 1991). We found that NE is slightly higher in concentration in the mouse $\mathrm{CN}$ and was placed on the amount of rewards the animal could receive (but the physical limit would be 360 rewards). Mice were not cued to the duration or that it is elapsing. Learning is assessed by measuring average timing of lever presses after the last press. To extract lever press timestamps for the RL) task from the Med Associates data output, MATLAB scripts were used. The lever press timestamps were binned by their interpress intervals while being sorted into either occurring after a rewarded press or a press within $3 \mathrm{~s}$ of a reset. Experimental and control mice were compared using a two-way repeated-measures ANOVA (viral group $\times$ week of training).

Delayed alternation. To gauge working memory, we used an operant version of a delayed alternation paradigm as previously described, with minor alterations (Locke et al., 2018). Mice began training on the delayed alternation paradigm the day after they completed $4 \mathrm{~d}$ of lever training on an FR1 schedule. In this paradigm, mice were first presented with a free choice of pressing one of two levers. After choosing which lever to press, a time interval of 2,8 , or $16 \mathrm{~s}$ ensued, during which both
CCtx than what was previously reported in rats (Versteeg et al., 1976). DA and its metabolites, DOPAC and HVA, were lower in concentration in the mouse $\mathrm{CN}$ and CCtx than previously reported in rats (Versteeg et al., 1976), and were not measurable in every sample. Epinephrine was not detected anywhere in the mouse brain that we examined, and the DA metabolite 3-MT was only detected in the striatum (Table 1). NE and DA levels in frontal cerebral cortex and striatum in mouse were similar as previously measured in rats (Table 1) (Versteeg et al., 1976).

\section{Mapping catecholaminergic fibers in the cerebellum and inputs to the LCN}

$\mathrm{TH}$ is found in fibers projecting to all cerebellar lobules, laminae, and nuclei in mouse, but relative quantification differences 
within the cerebellum are not described (Nelson et al., 1997). We first wished to confirm and quantify protein expression of $\mathrm{TH}$, the rate-limiting enzyme in catecholamine synthesis, in the entire cerebellar system, including the all regions of the CCtx (Figs. $1 A$, $2 A)$, the lateral, interposed, and medial nuclei of the cerebellum (Figs. $1 B-E, 2 B, D$ ), and several known pre-CN (Fig. $2 B$ ). We previously mapped all $\mathrm{TH}^{+}$PCs (Fig. $2 C$; reprinted from Locke et al., 2020), and show this data here for comparison to mapping of $\mathrm{TH}^{+}$fibers in Figure $2 \mathrm{~A}$. In the CCtx, $\mathrm{TH}^{+}$fiber expression was consistently higher in the molecular layer than the granular layer (Figs. 1A, 2A). $\mathrm{TH}^{+}$fibers were highest in anterior vermis (lobules II-IV), followed by posterior vermis regions (lobules VII, VIII), and two lateral hemisphere regions (simple lobule and the copula of pyramidis) (Fig. 2A), which notably are areas of CCtx with lowest amounts of $\mathrm{TH}^{+}$PCs (Fig. 2C). The lateral and interposed nuclei had equivalent amounts of $\mathrm{TH}^{+}$fibers and had the highest amount of TH staining of anywhere we measured in the cerebellar system (Fig. $2 B$ ). The LCN was distinctive, in that it had the most change in rostrocaudal expression (lowest expression rostrally) among the $\mathrm{CN}$ (Fig. $2 D$ ). There was quite variable expression of $\mathrm{TH}$ in known pre-CN, with the highest amounts being found in the RtTg, the IO nucleus, and the LRN (Fig. 2B). Additionally, there appeared to be a rostrocaudal gradient of $\mathrm{TH}$ expression in the basilar pontine nuclei (Fig. $2 B$ ).

We then wished to determine the source of catecholamines within the LCN. The LC is known to supply NE to CCtx (Bloom et al., 1971; Grzanna and Molliver, 1980). In mice, possible sources of catecholamines in the LCN include the LC (C. C. Smith and Greene, 2012; Kempadoo et al., 2016; Takeuchi et al., 2016; Sanford et al., 2017), PCs (Fujii et al., 1994; Locke et al., 2020), basal ganglia (Bostan et al., 2010), VTA (Ikai et al., 1992), and central NE nuclei (e.g., CA2/A2) in the brainstem (Robertson et al., 2013). Based on these reports, we injected 4 DBH-IRES-Cre mice (heterozygous for the DBH-IRES-Cre allele) crossed with TdTomato reporter mice with green retrobeads into the LCN (Fig. $3 A-F$ ). We found overlap of retrobeads and tomato staining in the LC, suggestive of projections to LCN (Fig. $3 A-E$ ). In order to confirm this retrograde method, we injected the anterograde adeno-associated virus (AAV1) containing a Cre-dependent expression cassette for the synaptic marker synaptophysin fused to GFP (AAV1-DIO-SynGFP) (Carter et al., 2013) into the LC in $D B H$-IRES-Cre mice, and found robust GFP expression in the LCN (Fig. 3G,H). Several reports have noted the presence of TH expression in a subset of PCs, which could potentially provide catecholamines to CN (Hess and Wilson, 1991; Takada et al., 1993; Fujii et al., 1994; Abbott et al., 1996). We confirmed that injection of green retrobeads in the LCN results in colocalization with $\mathrm{TH}$ expression (but not DBH-IRES-Cre driven tomato expression) in PCs (Fig. 4A-C). We did not further pursue mapping the innervation of the $\mathrm{LCN}$ by $\mathrm{TH}^{+} \mathrm{PCs}$, as we have recently mapped this population of cells in the entire cerebellum of mouse (Locke et al., 2020). Notably, we did not see colabeling of retrobeads and TH expression in other noradrenergic or dopaminergic nuclei, such as the VTA, CA2/A2, substantia nigra pars compacta, dorsal raphe, or retrorubral fields (Fig. $5 A-F$ ). We also injected SNc and VTA of DAT-Cre mice (heterozygous for the DAT-Cre allele) with AAV1-DIO-SynGFP and did not find any GFP expression in the LCN (Fig. 6A-F), consistent with a previous report of retrograde mapping with CAV2-Cre injected into CCtx of a mouse reporter line, which failed to reveal any labeling in VTA (Wagner et al., 2017). Finally, to generate projection maps for catecholamine-positive populations projections in LC for cell counting, we injected the retrograde adeno-
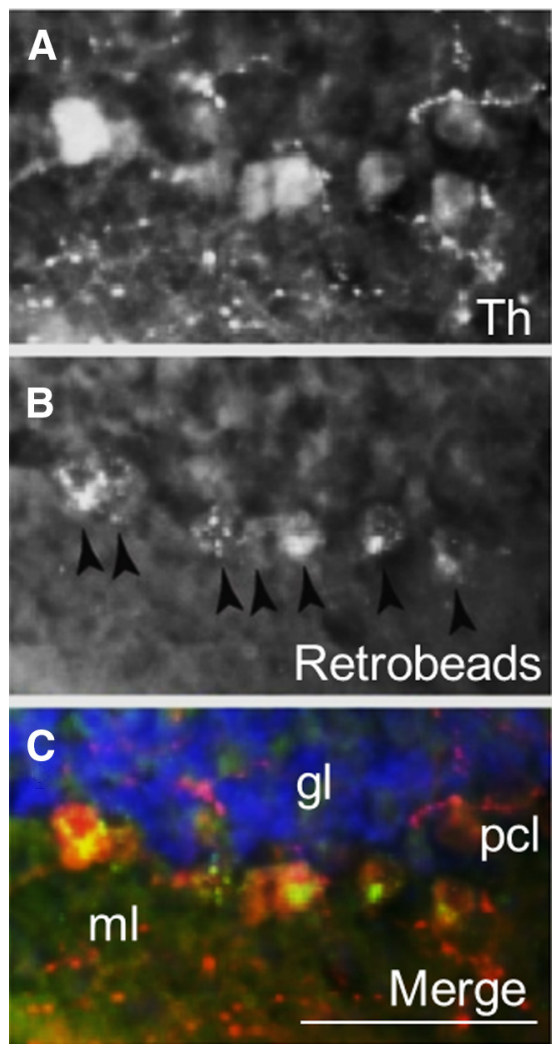

Figure 4. Colocalization of TH expression in PCs with green retrobeads. $\boldsymbol{A}$, TH stain (red color channel). $\boldsymbol{B}$, Retrobeads (green color channel). $\boldsymbol{C}$, Merged image of $\boldsymbol{A}, \boldsymbol{B}$, and DAPI (blue channel), Scale bar, $100 \mu \mathrm{m}$.

associated virus viral vector, AAV2retro (Tervo et al., 2016), containing a Cre-dependent expression cassette for the fluorophore, GFP (AAV2retro-DIO-GFP) into the LCN in 4 DBH-IRES-Cre (heterozygous for the DBH-IRES-Cre allele) (Fig. $7 A-G$ ). We then quantified cells positive for both $\mathrm{TH}$ and GFP in these animals, which make up $\sim 12 \%$ of the entire LC (Fig. $7 G$ ). Projections to LCN primarily arise from caudal and middle LC regions, with cells appearing throughout the dorsoventral axis of LC, and to a lesser extent, rostral LC and the adjacent noradrenergic nucleus, subcoeruleus (Fig. $7 A-C$ ). Previous reports of projections from LC to CCtx in rat are slightly different and were not precisely quantified, and consist of large, multipolar cells primarily in the middle LC throughout the dorsoventral axis (but not caudal LC, from which arise hippocampal projections) (Loughlin et al., 1986b). Furthermore, there are several reports of LC projections that diverge from the same LC neuron to project to both cerebellar cortical and cortical targets (Olson and Fuxe, 1971; Nagai et al., 1981; Room et al., 1981; Steindler, 1981; Schwarz et al., 2015). We saw labeled fibers in the LCN (Fig. 7D), but we did not see divergent projections to both LCN and noncerebellar targets, and we saw only sparse GFP puncta in areas of the CCtx, primarily in paravermal and lateral cerebellar regions (Fig. $7 F$ ). This may be either because of the LC-LCN projection being different from LC-CCtx projections, or limitations of the retrograde viral approach.

\section{FSCV of LC projections to the LCN}

Since the concentration of NE present in the LCN was greater than an order of magnitude more than what we could measure in DA, we hypothesized that the LC is a sufficient source of catecholaminergic innervation of the LCN. To further confirm this, 


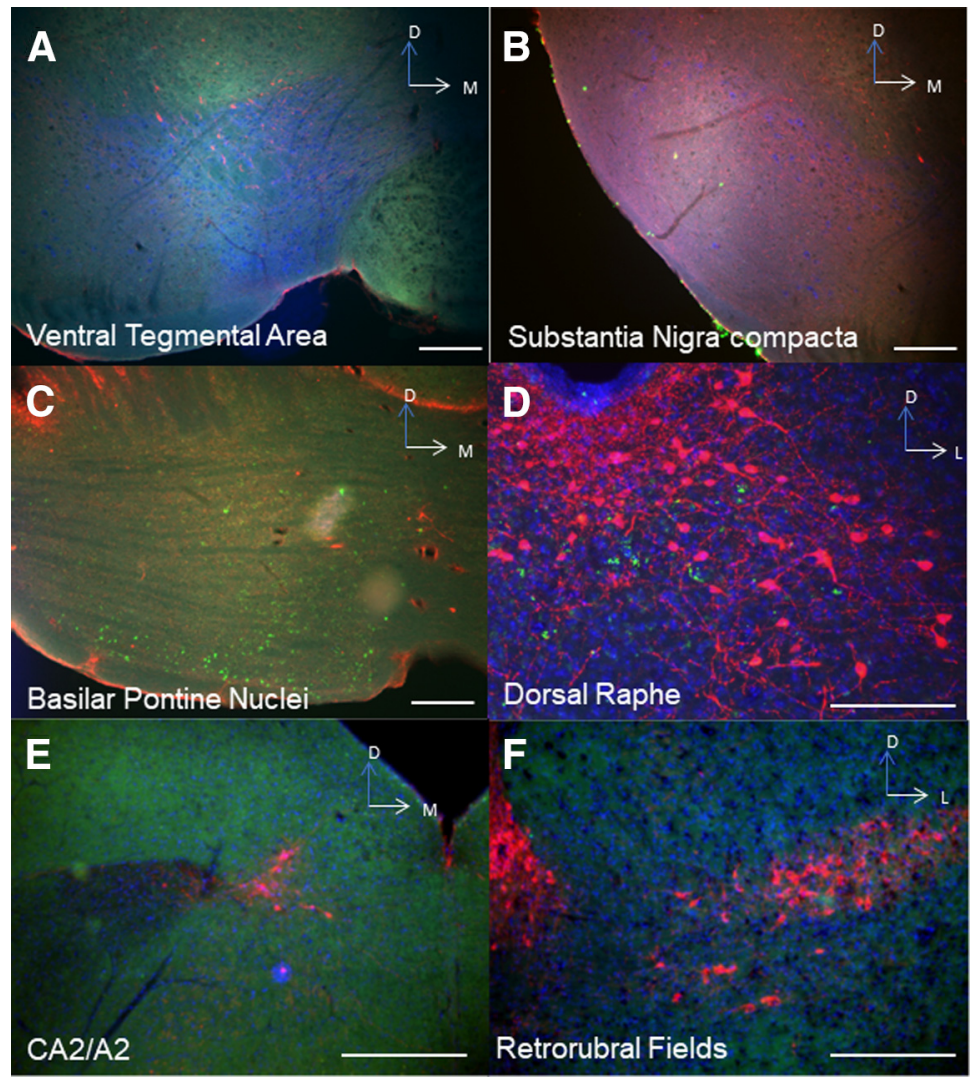

Figure 5. Extrinsic catecholaminergic innervation of the $L C N$ was found only from the $L C$ and subcoeruleus (not pictured in this figure) with retrobeads. Red represents TH. Blue represents DAPI. Green represents retrobeads. No overlap between retrobeads and $\mathrm{TH}^{+}$cells was seen in VTA $(\boldsymbol{A})$ (red represents DBH-IRES-CRE:::DsRed; blue represents TH; green represents retrobeads); substantia nigra pars compacta $(\boldsymbol{B})$ (red represents DBH-IRES-CRE::DsRed; blue represents $\mathrm{TH}$; green represents retrobeads); basilar pontine nuclei $(\boldsymbol{C})$, expected retrobead labeling of cells projecting mossy fibers to cerebellum, but these are not $\mathrm{TH}^{+}$(red represents $\mathrm{TH}$; blue represents DAPI; green represents retrobeads); dorsal raphe (D) (red represents TH; blue represents DAPl; green represents retrobeads); CA2/A2 noradrenergic brainstem nuclei $(\boldsymbol{E})$ (red represents TH; blue represents DAPI; green represents retrobeads); or the retrorubral fields $(\boldsymbol{F})$ (red represents TH; blue represents DAPl; green represents retrobeads). Scale bars, $250 \mu \mathrm{m}$.

we used electrophysiological stimulation of the LC and direct recordings of catecholamine levels in the LCN using FSCV. NE and DA are detected by their oxidation and reduction on the surface of the electrode, which is proportional to their local concentration (Rodeberg et al., 2017). Currently, we are not able to differentiate between DA and NE with this method, but we are unaware of any reported use of FSCV in the cerebellum to detect changes in catecholamines.

We stimulated the LC in 13 anesthetized WT mice (Fig. 8A), at a frequency of $60 \mathrm{~Hz}$ for $1 \mathrm{~s}$ (amplitude $=250 \mu \mathrm{A}$ ) and recorded cyclic voltammograms (CVs) from the ipsilateral LCN (Fig. $8 B$; stimulation and recording site examples in Fig. $8 C, D$ ). In Figure $8 E$, we show an example catecholamine transient above a color plot of the recording. An experimental $\mathrm{CV}$ is overlain in the figure by a known DA CV (Fig. 8E), which shows strong similarity. Since FSCV does not directly differentiate well between different catecholamines, we sought to determine whether pharmacologic antagonism of presynaptic receptors for DA or NE on LC projections to the LCN would potentiate the catecholamine transient in this preparation. Previous reports indicate that LC fires primarily in the $1-10 \mathrm{~Hz}$ frequency range during awake, behaving conditions (AstonJones and Cohen, 2005). We were not specifically interested in mimicking a physiological firing, but rather seeing if the LC provided an input that was sufficient to induce a catecholamine signal in carbon fibers in the LCN, and what the identity of the NT was. Thus, after acquiring stable catecholamine transients, we applied intraperitoneal injections of either the DA D2R antagonist eticlopride $(N=7$, intraperitoneal injection, concentration $=0.5 \mathrm{mg} / \mathrm{kg}$ ) or the adrenergic alpha-2 receptor antagonist idazoxan $(N=4$, intraperitoneal injection, concentration $=1 \mathrm{mg} /$ $\mathrm{kg})$. We averaged the last four transients before drug administration and compared them with the average of the first four transients after drug administration (Fig. 8F). Application of eticlopride did not result in potentiation of the catecholamine signal (Fig. 8F,G,I); however, application of idazoxan resulted in a twofold potentiation of the catecholamine signal over baseline (Fig. 8F,H,I).

It is possible that the catecholamine signal we observed in LCN could result from stimulation of cross-circuit connections. Nevertheless, these data are strongly suggestive of the LC being a major source of catecholamines, likely NE, in the LCN.

\section{Genetic inactivation of $T h$ in the LCN}

We used the retrogradely transducing canine adenovirus CAV2 encoding Cre recombinase in male $T h^{\text {lox/lox }}$ mice (Jackson et al., 2012) to knock out $T h$ in all neurons located in or projecting to the LCN (Fig. 9A). We previously did not see significant differences in performance between male and female mice in the cognitive tasks we examined after our manipulations in the LCN (Locke et al., 2018). Thus, we selected only male mice for this study. We wished to examine the role of catecholamines in LCN in adult mice, so behaviors were performed between the ages of 3 and 5 months. We injected 10-week-old homozygous for the Th lox allele $\left(T h^{\text {lox/lox }}\right)$ mice with CAV2-Cre into the LCN (Fig. 9A). Littermate $T h^{\text {lox/lox }}$ mice controls were injected with CAV2 encoding the fluorophore zsGreen (CAV2-zsGreen). Viral "hits" were verified by Western blot of LCN tissue isolated by tissue punch of a section of cerebellum (Fig. 9B,C). TH was reduced by $75 \%$ in the LCN with this manipulation (Fig. 9C). We additionally confirmed LCN-Th-cKO with immunohistochemical staining for $\mathrm{TH}$ in control virus (CAV2-zsGreen) injected controls (Figs. 9D, 10A) and CAV2-Cre injected Th ${ }^{\text {lox/lox }}$ mice (Fig. 9E). To further control for viral spread/expression, we also injected mice heterozygous for the Slc17a6-Cre allele (Vglut2-Cre) mice (Slc17a6 encodes the vesicular glutamate transporter-2 [Vglut2], the major vesicular glutamate transporter expressed in CN output neurons) with AAV1-DIO-GFP and examined GFP expression in the LCN, where it appeared well limited to LCN, but not other cerebellar nuclear structures (Fig. 10B).

LCN catecholamines modulate sensorimotor gating, but are not required for locomotor function, motor learning, or auditory startle responses

Cerebellar NE has previously been shown to be necessary for classical cerebellar functions, such as adaptation of the vestibulo- 
ocular reflex and eyeblink conditioning (Watson and McElligott, 1983, 1984; Paredes et al., 2009), and motor learning of rod runway task (Watson and McElligott, 1984; Bickford et al., 1992). We hypothesized that since cognitive functions are associated with $\mathrm{LCN}$ and posterior and lateral regions of CCtx, we would not see major sensorimotor effects in LCN-Th-cKO mice. LCN-ThcKO mice did not have changes in performance on the accelerating rotarod, which is dependent on cerebellar function (Caston et al., 1995a,b) (Fig. 9F). We also used prepulse inhibition of the acoustic startle reflex (PPI) as a standard test for sensorimotor gating, which is thought to engage preattention systems, and is modulated by the cerebellum (Takeuchi et al., 2001; Locke et al., 2018). While LCN-Th-cKO mice showed decreased PPI (Fig. 9G), this did not appear to be dependent on motor or auditory function, as there were no differences in their baseline acoustic startle reflex [mean percent \pm SEM startle magnitude with null prepulse in LCN-Th-cKO mice $=75.14 \pm 6.64 \quad(n=11)$ vs Control mice $=86.52 \pm 2.26 \quad(n=10)$, $p=0.14$, unpaired two-tailed $t$ test, $t=1.56$, $\mathrm{df}=19]$, which is also cerebellar-dependent (Davis et al., 1982). Finally, we examined gait in LCN-Th-cKO mice and found a small $(\sim 6 \%)$ but significant increase in stride length (but not stride width) (Fig. 10J). This is not consistent with an ataxic phenotype, in which stride length dramatically decreases (Cendelin et al., 2010). Clinically, disturbances in vestibular function may be manifested as reduced visual acuity and gaze stability in humans, and rodents with deficits in vestibular function show spatial navigation deficits in tasks dependent on visual cues (P. F. Smith et al., 2009, 2010, 2015; Zheng et al., 2009a,b). Thus, we hypothesized that, if there were perturbations in cerebellar modulation of vestibular function, we would see it in performance deficits on the Barnes Maze, a spatial navigation task that relies on learning extra-maze visual spatial cues. However, LCN-Th-cKO mice did not show any differences in spatial memory as measured by nose pokes in the goal quadrant [mean number of nose pokes in goal quadrant \pm SEM in $\mathrm{LCN}-$ Th - cKO mice $=73 \pm 16(n=11)$ vs Control mice $=70 \pm 20$ ( $n=10), p=0.89$, unpaired two-tailed $t$ test, $t=0.14, \mathrm{df}=19$ ) or goal (mean number of nose pokes in goal \pm SEM in LCN-Th$c K O$ mice $=49 \pm 13(n=11)$ vs Control mice $=52 \pm 17(n=10)$, $p=0.88$, unpaired two-tailed $t$ test, $t=0.15, \mathrm{df}=19]$ on the probe trial or the Barnes Maze.

\section{Catecholamines in the $\mathrm{LCN}$ required for Pavlovian fear learning}

We hypothesized that we would see decreased discrimination between predictive and nonpredictive auditory cues in LCN-ThcKO mice because cerebellum is known to process signals predicting perceptual cues (O'Reilly et al., 2008). In order to test this, we used a fear conditioning paradigm in which the subject is exposed to an auditory cue (a specific tone, $\mathrm{CS}^{+}$) predictive of a low-amplitude foot shock $(0.3 \mathrm{~mA}, 0.5 \mathrm{~s})$ and an auditory cue of different frequency that is not predictive of the shock $\left(\mathrm{CS}^{-}\right)$ (Sanford et al., 2017). This test requires that a subject learn a cue that predicts a shock and discriminate between cues to freeze (learning is measured by the amount of freezing after playing $\mathrm{CS}^{+}$or $\mathrm{CS}^{-}$during the probe trial) in the context of a predicted shock (Fig. 9H). After $1 \mathrm{~d}$ of conditioning, LCN-Th-cKO mice were freezing more to the $\mathrm{CS}^{-}$than controls (Fig. 9I). On the second probe trial, $\mathrm{LCN}-\mathrm{Th}-\mathrm{cKO}$ mice were unable to discriminate between $\mathrm{CS}^{+}$and $\mathrm{CS}^{-}$(Fig. 9I), although it appears that this is because LCN-Th-cKO mice failed to fully learn to associate $\mathrm{CS}^{+}$with the shock, as opposed to inappropriately identifying $\mathrm{CS}^{-}$as a fear predictive cue.

\section{LCN catecholamines modulate learning of a working memory task}

Delayed alternation is a name for several similar tasks measuring working memory that can be evaluated in humans and animals, and has deficits in neuropsychiatric disorders with associated prefrontal cortical catecholaminergic dysfunction, including autism, Alzheimer's disease, attention deficit disorder, schizophrenia, and frontal lobe disease (M. Freedman and Oscar-Berman, 1986a,b; Park and Holzman, 1992; M. Freedman, 1994; Arnsten and Li, 2005; Arnsten, 2006a,b; Berridge et al., 2006; Loveland et al., 2008; Rossi et al., 2012). In the delayed alternation task we used in this study, the subject chooses one of two levers, levers retract, and then there is a delay of $2 \mathrm{~s}$ (Fig. 9J). The subject must learn a specific rule of pressing the other lever to receive a food reward after the delay (Fig. 9J). Performance on this task, over longer intervals of delay, requires an intact PFC (Rossi et al., 2012) and LCN neurons expressing D1Rs (Locke et al., 2018). Learning is assessed as fraction of correct alternations out of each opportunity (Fig. 9K), and number of pellets delivered (Fig. 9L). LCN-TH-cKO mice showed a decreased rate of learning on this task (Fig. $9 K, L$ ). However, once they learned this task, they 

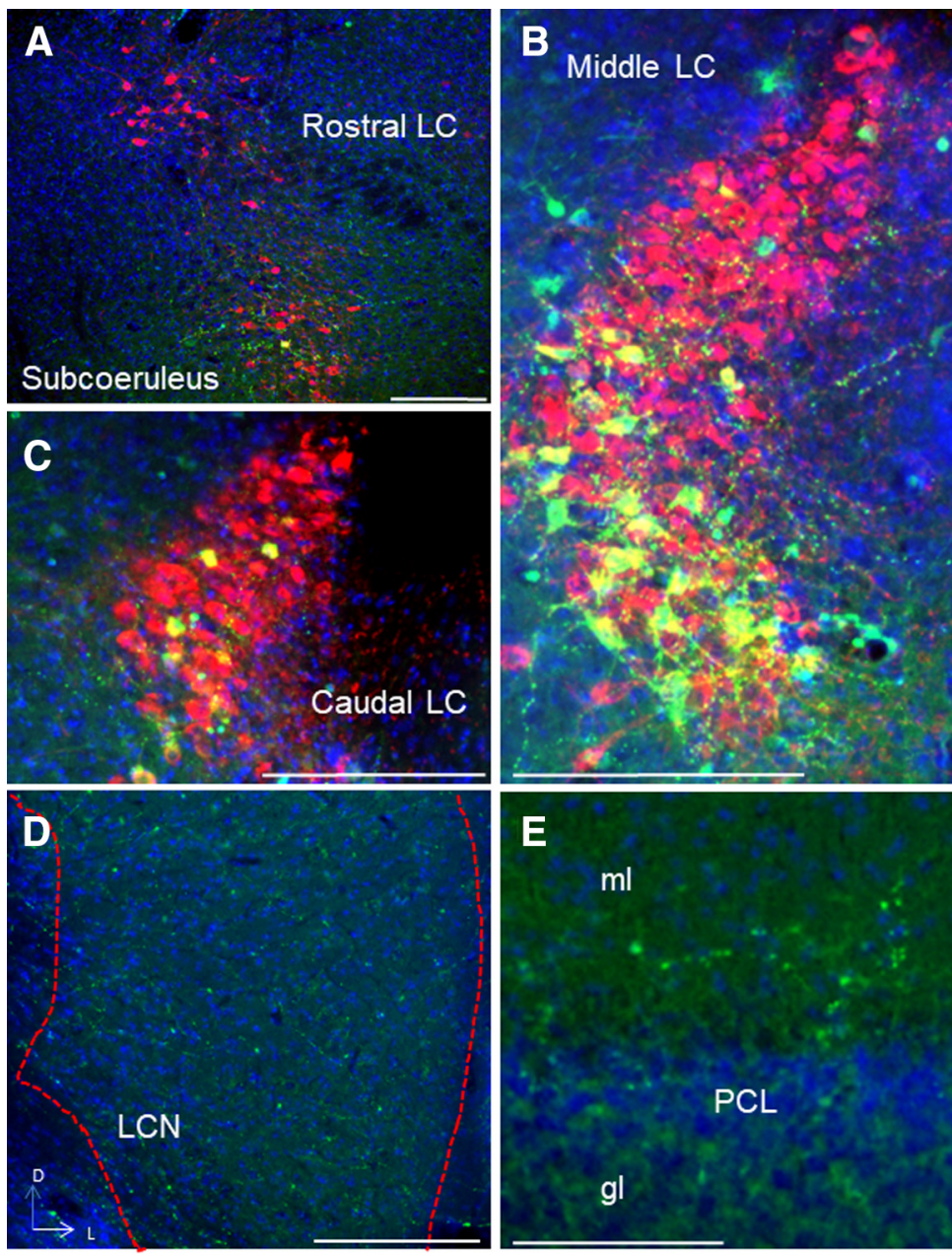

$\mathbf{F}$

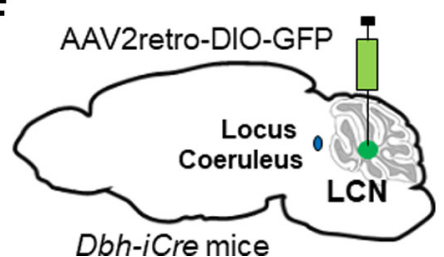

Figure 7. Example slides of extrinsic catecholaminergic innervation of the LCN in LC mapped with retrograde viral expression RetroAAV2-DI0-GFP injected into LCN of DBH-IRES-Cre mice in coronal sections. Cells were stained with TH (red channel), GFP (green channel), and DAPI (blue channel). A-C, Examples of cells coexpressing TH and GFP in the merged image. $\boldsymbol{A}$, Example of cells coexpressing TH (red), DAPI (blue), and GFP (green) in nucleus subcoeruleus in a merged image. $\boldsymbol{B}$, Example of cells coexpressing TH (red), DAPI (blue), and GFP (green) in middle LC in a merged image. C, Example of cells coexpressing TH (red), DAPI (blue), and GFP (green) in caudal LC in a merged image. D, Fibers expressing GFP in LCN. E, Sparse fibers express GFP in CCtx. MI, Molecular layer; gl, granular layer; PCL, PC layer. $\boldsymbol{F}$, Schematic of injection of AAV2retro-DI0-GFP into LCN of Dbh-IRES-Cre mice. G, Quantification of $\mathrm{GFP}^{+}$and $\mathrm{TH}^{+}$cells in different regions of LC after injection of AAV2retro-DI0-GFP into LCN of Dbh-IRES-Cre mice. $\boldsymbol{F}$, Adapted from Franklin and Paxinos (2013). Scale bars: $\boldsymbol{A}-\boldsymbol{E}, 250 \mu \mathrm{m}$.

showed relatively normal performance when the delay was increased to $8 \mathrm{~s}$ (Fig. 10C,E,I), and a small decrease in performance when the delay was increased to $16 \mathrm{~s}$ (Fig. 10C,F,J), and no changes in performance on the reversal of this task (Fig. 10C,G, $K)$. Thus, it appears that learning the delayed alternation task was affected more than working memory maintenance over longer time scales. This did not appear to be because of effects of motor deficits in lever pressing, as mice acquired FR1 at the same rate (Fig. 10C,D) or anxiety, as LCN-Th-cKO mice did not show any apparent anxiety in the open field test: [mean time (s) spent in center of open field \pm SEM in LCN-Th-cKO mice $=157.7 \pm 28.5 \quad(n=11) \quad$ vs $\quad$ Control mice $=135.5 \pm 18.7 \quad(n=10), \quad p=0.53$, unpaired two-tailed $t$ test, $t=0.64, \mathrm{df}=19$; mean velocity $(\mathrm{cm} / \mathrm{s})$ in open field \pm SEM in $\mathrm{LCN}-\mathrm{Th}-\mathrm{cKO}$ mice $=6.06 \pm 0.4(n=11)$ vs Control mice $=6.19 \pm 0.4(n=10), p=0.82$, unpaired two-tailed $t$ test, $t=0.23, \mathrm{df}=19$; center crossings in open field \pm SEM in $\mathrm{LCN}-\mathrm{Th}-\mathrm{cKO}$ mice $=45.3 \pm 6.1 \quad(n=11)$ vs Control mice $=52 \pm 7.3 \quad(n=10), p=0.47$, unpaired two-tailed $t$ test, $t=0.23, \mathrm{df}=19]$.

\section{LCN catecholamines modulate response inhibition}

Catecholamines modulate response inhibition in prefrontal cortical circuits (Arnsten and $\mathrm{Li}, 2005$ ); we thus hypothesized that LCN catecholamines play a similar role. To test this, we chose an operant task called DRL to assess the ability to inhibit responses until a specific time has elapsed (Nautiyal et al., 2015). No differences in the ability to press a lever for a food reward were seen over $4 \mathrm{~d}$ of FR1 lever training between groups (Fig. 10D). A given subject must learn to inhibit lever press responses for the duration (10 s for DRL-10) to receive the reward (Fig. 9M). We assessed performance on this task by number of lever presses within $3 \mathrm{~s}$ after the last rewarded press (which we refer to as "impulsive pressing"). LCN-Th-cKO mice showed more impulsive pressing after the last press (or more failure to inhibit responses) than littermate controls over several weeks of training (Fig. 9N).

\section{Inhibition of VGlut ${ }^{+}$LCN output neurons facilitates learning of delayed alternation working memory task}

Catecholaminergic fibers richly innervate the LCN, but little is known about which cells catecholamine release might regulate there. Recently, we showed expression of D1R, $\mathrm{D} 2 \mathrm{R}$, and D3R in the LCN, and that there is a population of LCN D1R ${ }^{+}$neurons, which are mostly inhibitory and regulate several aspects of cognitive behavior (Locke et al., 2018). DA D1Rs have much less affinity for NE than DA (Sunahara et al., 1990), but there are reports that D1Rs can be activated by the $\beta$-adrenergic agonist isoproterenol (Lin et al., 1995) and NE (Vanderheyden et al., 1986; Kubrusly et al., 2007). We also showed that Vglut $^{+}$neurons residing in the $\mathrm{LCN}$ are enriched in the DA D3R, which is canonically a Gi-coupled protein coupled receptor. Furthermore, activation of right crus I PCs and inhibition of LCN neurons were sufficient to rescue autism-related social behavior and aberrant single-unit firing in neurons in the prelimbic medial PFC (Kelly et al., 2020). Since the D2 family of DA receptors canonically reduce PKA signaling and neural excitability via $G_{i / o}$ GPCR signaling, and are potently activated by both NE and DA (Sánchez-Soto et al., 2016), we hypothesized that catecholamine release in the LCN would result in catecholamine-induced 
activation of $\mathrm{G}_{\mathrm{i}}$-coupled catecholamine receptor GPCRs and inhibit VGlut ${ }^{+}$LCN output neurons and positively facilitate cognitive function. To test this, we first performed immunohistochemistry for the DA D2R in the LCN and found rich expression in large soma of cells there (Fig. 11A,B). Then, to mimic the activation of Gi-coupled catecholamine GPCRs, we expressed the inhibitory DREADD, hM4Di or GFP (Controls), in the LCN of Vglut2-Cre mice. To accomplish this, we injected $0.5 \mu \mathrm{l}$ of AAV-FLEX-hM4Di-YFP or AAV-FLEX-GFP into the LCN of heterozygous Vglut2-Cre mice to create Vglut2-Cre::hM4Di or Control (Vglut2Cre::GFP) mice (Fig. 11C,D). Experimental Vglut2-Cre::hM4Di and Control Vglut2Cre::GFP mice both were pretreated with CNO ( $1 \mathrm{mg} / \mathrm{kg}$, i.p.) $45 \mathrm{~min}$ before all behavioral assessments. After lever training on an FR1 schedule (Fig. 11E,F), we performed the same delayed alternation paradigm as we did for LCN-Th-cKO mice (Fig. $11 E-K$ ); and strikingly, learning on the $2 \mathrm{~s}$ DA was robustly facilitated in Vglut2-Cre::hM4Di mice compared with controls (Fig. 11G). Once they learned this task, Vglut2-Cre::hM4Di mice showed better than normal performance when the delay was increased to 8 or $16 \mathrm{~s}$, at least on the measure of pellets rewarded (Fig. $11 \mathrm{H}$, I). There appeared to also be a small increase in performance in Vglut2-Cre:: $h M 4 D i$ mice on the reversal of this task: the significance did not quite reach our $\alpha$ of $p<0.05$ (Fig. $11 K$ ), but post hoc analysis revealed that Vglut2-Cre::hM4Di mice received significantly more pellets on the first day of the delayed alternation reversal. Vglut2-Cre::hM4Di mice did not have changes in ability to press a lever for food reward (Fig. 11E,F), acoustic startle responses [mean percent \pm SEM startle magnitude with null prepulse in Vglut2Cre: :hM4Di mice $=81.97 \pm 3.01 \quad(n=8)$ vs Control mice $=83.96 \pm 1.81 \quad(n=7)$, $p=0.25$, unpaired two-tailed $t$ test, $t=1.21$, $\mathrm{df}=13$ ], PPI (Fig. $11 M$ ), performance on the accelerating rotarod (Fig. $11 N$ ), or on measures of locomotion or anxiety on the open field test [mean time (seconds) spent in center of open field \pm SEM in Vglut2Cre:: hM4Di mice $=16.7 \pm 4.2 \quad(n=8) \quad$ vs Control mice $=20.7 \pm 6.1 \quad(n=7), p=0.62$, unpaired two-tailed $t$ test, $t=0.51, \mathrm{df}=13$; mean velocity $(\mathrm{cm} / \mathrm{s})$ in open field \pm SEM in Vglut2-Cre::hM4Di mice $=5.8 \pm 0.4$ $(n=8)$ vs Control mice $=6.1 \pm 0.6(n=7)$, $p=0.66$, unpaired two-tailed $t$ test, $t=0.45$, $\mathrm{df}=13$; center crossing frequency $\pm \mathrm{SEM}$ in Vglut2-Cre::hM4Di mice $=14.4 \pm 2.2 \quad(n=8)$ vs Control mice=17.7 $\pm 3.4 \quad(n=7)$, $p=0.42$, unpaired two-tailed $t$ test, $t=0.84, \mathrm{df}=13]$. and Paxinos (2013).

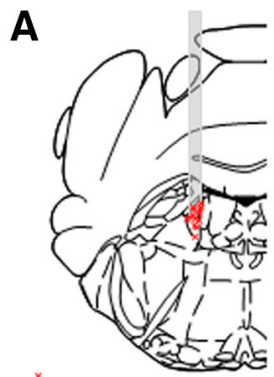

Stimulation site Locus Coeruleus

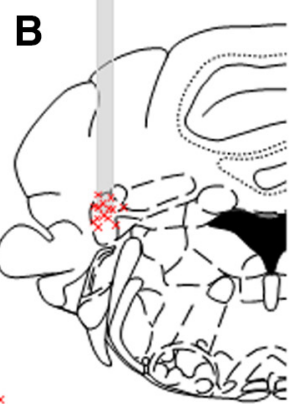

Carbon fiber electrode recording site

Lateral Nucleus of the Cerebellum

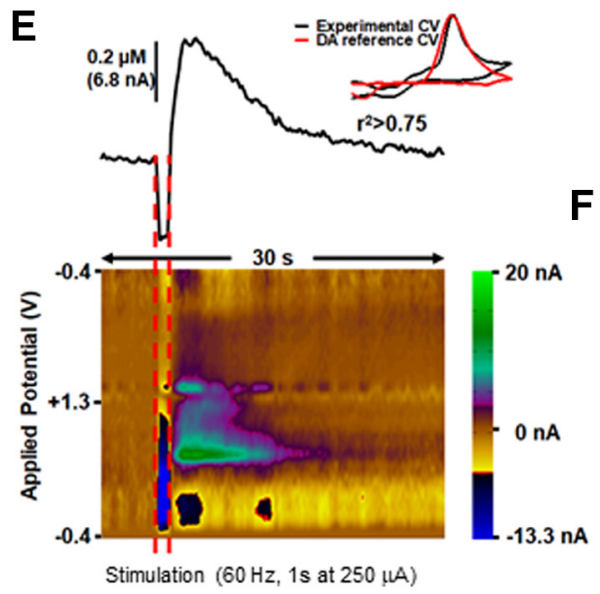

G

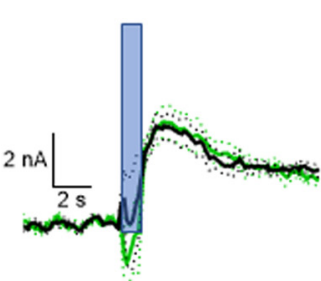

- Pre Drug — Post ETI
H

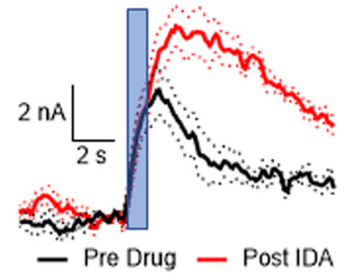

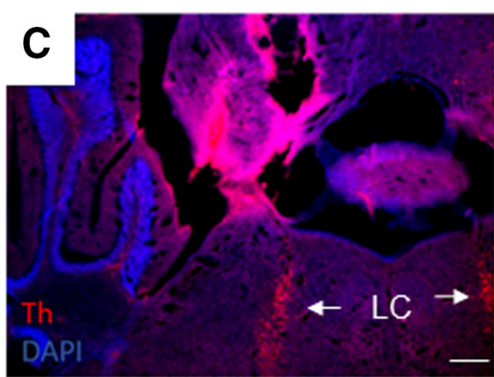

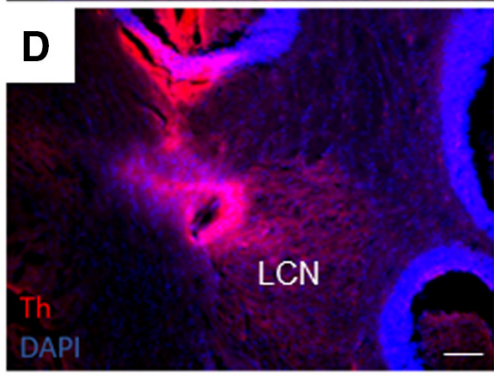

$\mathbf{F}$

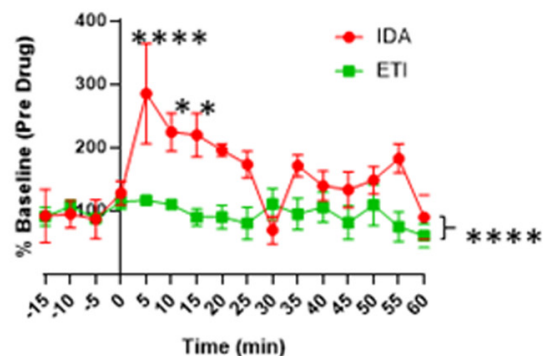

Figure 8. Recording of catecholamine transients in the LCN of mice on stimulation of the LC. $A$, Stimulation sites in 13 mice. Each red " $x$ " is a stimulation site confirmed by histology. Coronal section adapted from Franklin and Paxinos (2013). B, Carbon fiber electrode placement in 13 mice. Each red " $\mathrm{x}$ " is a recording site confirmed by histology. Coronal section adapted from Paxinos mouse atlas (Franklin and Paxinos, 2013). Stimulation in LC (fiber tract verification in C; arrows point at LC) results in a catecholamine signal in the lateral nucleus of the cerebellum (fiber tract verification in $\boldsymbol{D}$ ). Scale bars: $\boldsymbol{C}, \boldsymbol{D}, 250$ $\mu \mathrm{m}$. $\boldsymbol{E}$, Catecholamine transient recorded in LCN after stimulation of LC (red bars, $1 \mathrm{~s}$ duration, $60 \mathrm{~Hz}$ stimulation at 250 $\mu \mathrm{A})$. Top, Relative change in catecholamine level. Bottom, Color plot of transient. Inset, Example CV from LCN overlain with a reference DA CV. $\boldsymbol{F}$, Time course of pharmacologic experiments with either alpha-2 adrenergic antagonist idazoxan (IDA, red) or the DA D2 antagonist eticlopride (ETI, green) applied intraperitoneally. Main effect of drug: $F_{(1,144)}=41.10$, $p<0.0001$; interaction: $F_{(15,144)}=2.756, p<0.0009$. In graph stars, post hoc analysis Dunnett's multiple comparisons $q_{(144)}=4.823 . * * * * p<0.0001, q_{(144)}=3.311 ; 3.196$. $* p<0.05$ compared with measurement at -15 min. $\mathbf{G}$, Average CVs ( \pm SEM in dots) overlain before and after administration of the DA D2R antagonist eticlopride (intraperitoneal injection, concentration $=0.5 \mathrm{mg} / \mathrm{kg}$ ). $N=7$. Blue bar represents stimulus application: $60 \mathrm{~Hz}, 60 \mathrm{p}, 250 \mu \mathrm{A}$. $\boldsymbol{H}$, Average CVs ( \pm SEM in dots) overlain before and after administration of the adrenergic $\alpha 2$ receptor antagonist idazoxan (intraperitoneal injection, concentration $=1 \mathrm{mg} / \mathrm{kg}$ ). $N=4$. Blue bar represents stimulus application: $60 \mathrm{~Hz}, 60 \mathrm{p}, 250 \mu \mathrm{A}$. I, Type of drug $\times$ administration of drug interaction: $* * p<0.005, F_{(1,9)}=14.25$, post hoc analysis (Sidak's multiple comparison test); $t_{(9)}=4.834$, $p<0.005$; type of drug: not significant; administration of drug: $F_{(1,9)}=15.51 p<0.005$. $\boldsymbol{A}, \boldsymbol{B}$, Illustrations from Franklin

\section{Discussion}

Our experiments show that the mouse LCN and interposed nucleus (IN) have the greatest $\mathrm{TH}^{+}$fiber innervation of any part of the cerebellar system. TH expression was highest in regions 
A

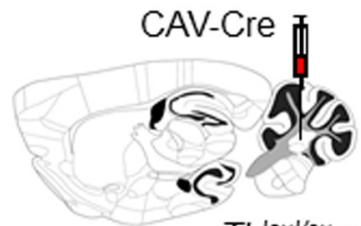

$T h^{\text {loxl/ox mice }}$
B

TH

$\beta$-actin

Protein extracted from
punches
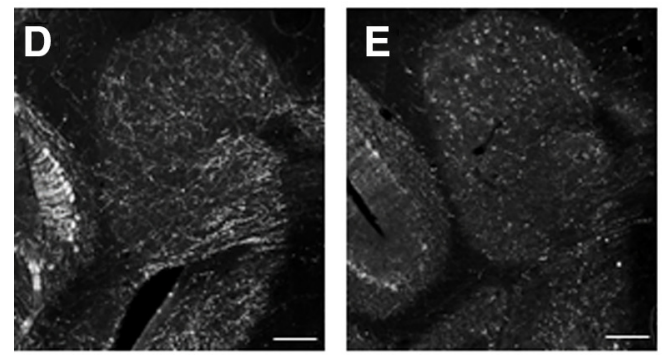

$\mathbf{F}$

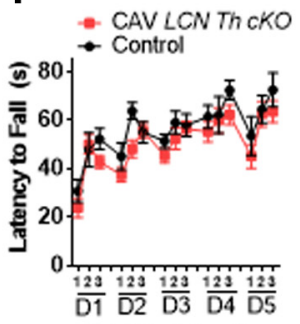

Trial/Training Day

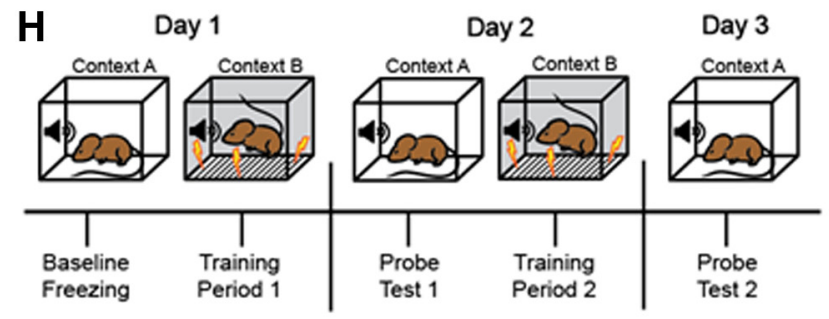

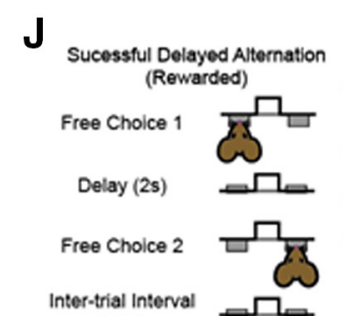

Inter-trial Interval

(20s)

\section{M}

K - CAV LCN Th CKO

$\mathbf{L}=$ CAV LCN Th CKO

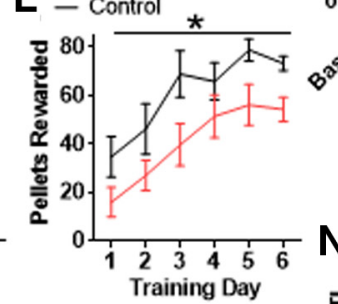

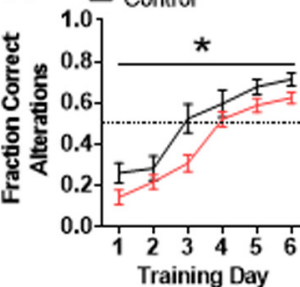

G

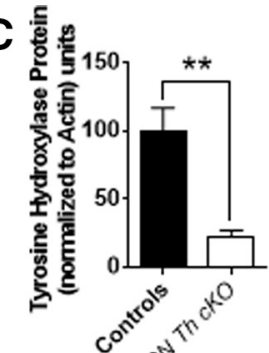<smiles></smiles>
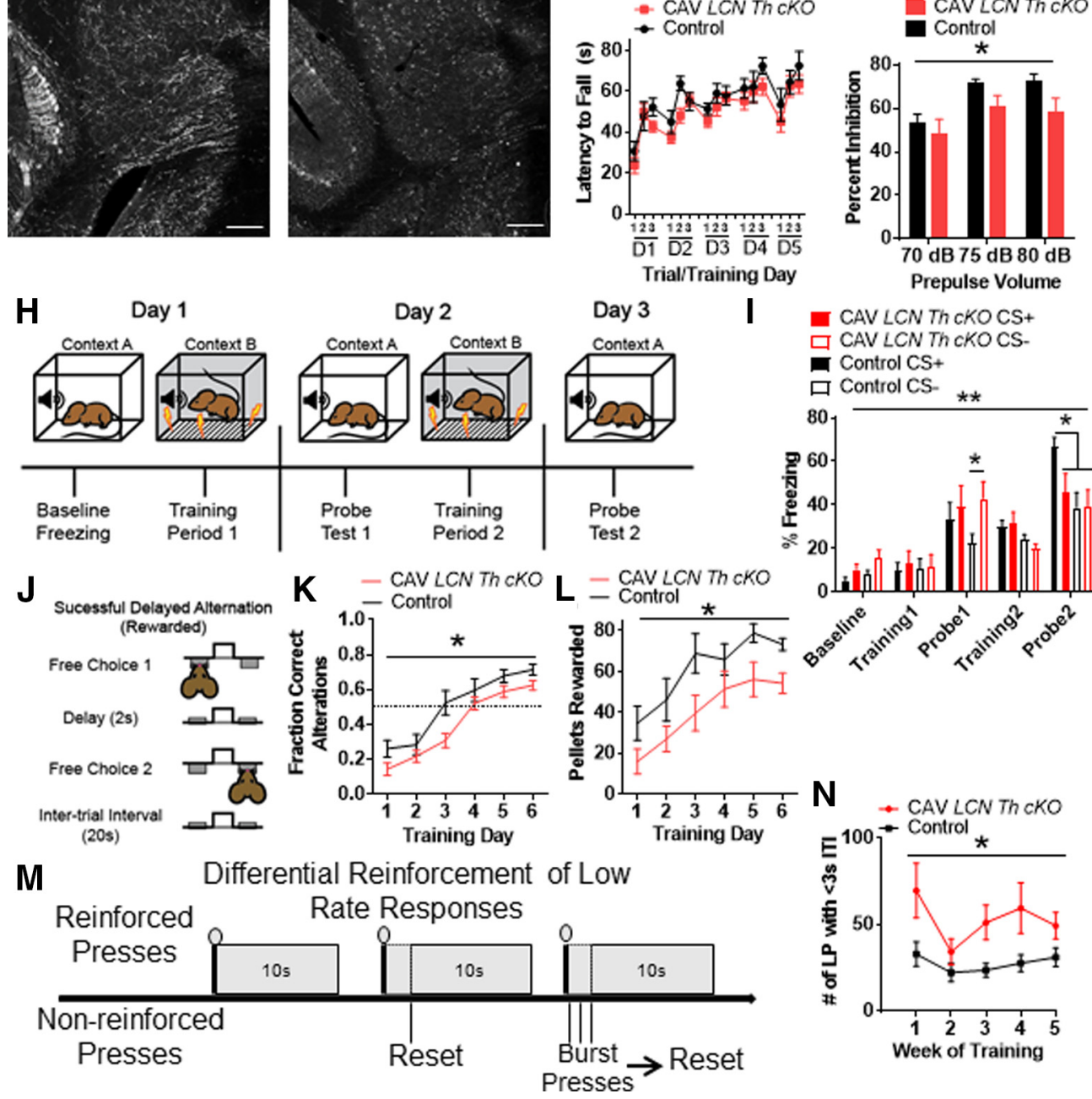

CAV LCN ThCKOCS+

CAV LCN Th CKO CS-

Control CS+

Control CS-
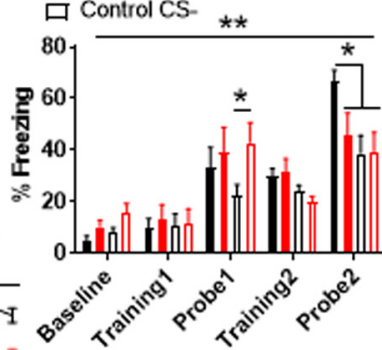

$\mathbf{N}$

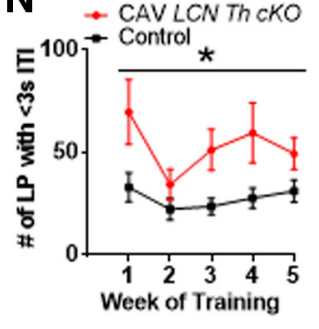

Figure 9. Conditional $K O$ of $T h$ in all fibers innervating the $L C N$ results in sensorimotor gating and cognitive deficits, but not motor learning deficits. A, Schematic for CAV2-Cre viral injection into $T h^{\text {lox } 10 x}$ mice into $L C N$ to generate $L C N$ Th conditional KO (LCN-Th-CKO) mice. B, Western blot with 3 representative CAV2-zsGreen controls on the left and 3 CAV2-Cre injected Th ${ }^{\text {loxlox }}$ mice on the right. Top, TH band. Bottom, $\beta$-actin band. C, Quantification of Western blot, each TH band normalized to $\beta$-actin. $* * p<0.01$ (one-tailed $t$ test, $t_{(4)}=4.47$ ). Staining of TH in red channel in LCN of control (D) and LCN-Th-CKO (E) mice. Scale bars: D, E, $100 \mu \mathrm{m}$. $\boldsymbol{F}$, Performance of CAV2-zsGreen injected littermate control (black) and LCN-Th-CKO mice on accelerating rotarod over $5 \mathrm{~d}$ of training. No difference observed between groups or effect of interaction with training. $N=10$ or 11 per group. G, Prepulse inhibition of the acoustic startle reflex was significantly different between LCN-Th-CKO mice and CAV2zsGreen injected littermate controls for effect of group $F_{(1,57)}=5.77,(* p<0.02)$ and effect of prepulse volume $F_{(2,57)}=5.63(* p<0.01)$, but not interaction between group and prepulse volume. $n=10$ or 11 per group. $\boldsymbol{H}$, Schematic for fear conditioning experiment. $\boldsymbol{I}$, Freezing after fear conditioning between LCN-Th-CKO mice and CAV2-zsGreen injected littermate controls on a fear discrimination task with a low-amplitude shock $(0.3 \mathrm{~mA}) . N=10$ in each group. There was an effect of training $F_{(4,144)}=39.37(p<0.0001)$ and effect of interaction between group and training $F_{(12,144)}=2.51$ $(* * p<0.01)$, but no effect of group, two-way repeated-measures ANOVA. On post hoc analyses (Bonferroni's multiple comparisons test), Control mice had less freezing to the CS ${ }^{-}$tone after $1 \mathrm{~d}$ of training compared with LCN-Th-CKO mice $(* p<0.05)$ and Control mice discriminated between $C S^{+}$and $C^{-}$after $2 \mathrm{~d}$ of conditioning, while LCN-Th-cKO mice did not $(* p<0.05)$. J, Schematic of delayed alternation test for working memory. Adapted from Beas et al. (2017). $\boldsymbol{K}$, Performance between LCN-Th-CKO mice and CAVZzsGreen injected littermate controls in delayed alternation with $2 \mathrm{~s}$ delay, as measured by fraction of correct alternations. $N=7$ in each group. There was an effect of training, $F_{(5,60)}=38.06(p<0.0001)$ and effect of group, $F_{(1,12)}=6.63$ (*p $\left.<0.03\right)$, but no effect of the interaction between group and training, two-way repeated-measures ANOVA. L, Performance between LCN-Th-CKO mice and CAVZzsGreen injected littermate controls in delayed alternation with $2 \mathrm{~s}$ delay, as measured by pellets rewarded. $N=7$ in each group. There was an effect of training, $F_{(5,60)}=19.46(p<0.0001)$ and effect of group, $F_{(1,12)}=6.2(* p<0.03)$, but no effect of the interaction between group and training, two-way repeated-measures ANOVA. $\boldsymbol{M}$, Schematic of differential reinforcement of low-rate responses test for impulsive pressing. Adapted from Locke et al. (2018). $\boldsymbol{N}$, Burst pressing performance (presses $<3 \mathrm{~s}$ after last rewarded press) between LCN-Th-CKO mice and CAV2-zsGreen injected littermate controls on DRL task over 5 weeks of training. $N=7$ in each group. There was an effect of training $F_{(4,48)}=3.47(p<0.02)$ and effect of group $F_{(1,12)}=6.38(* p<0.03)$, but no effect of the interaction between group and training, two-way repeated-measures ANOVA. $A$, Illustration from Franklin and Paxinos (2013). In each panel, asterisk indicates which comparison is noted by the significance bar. 


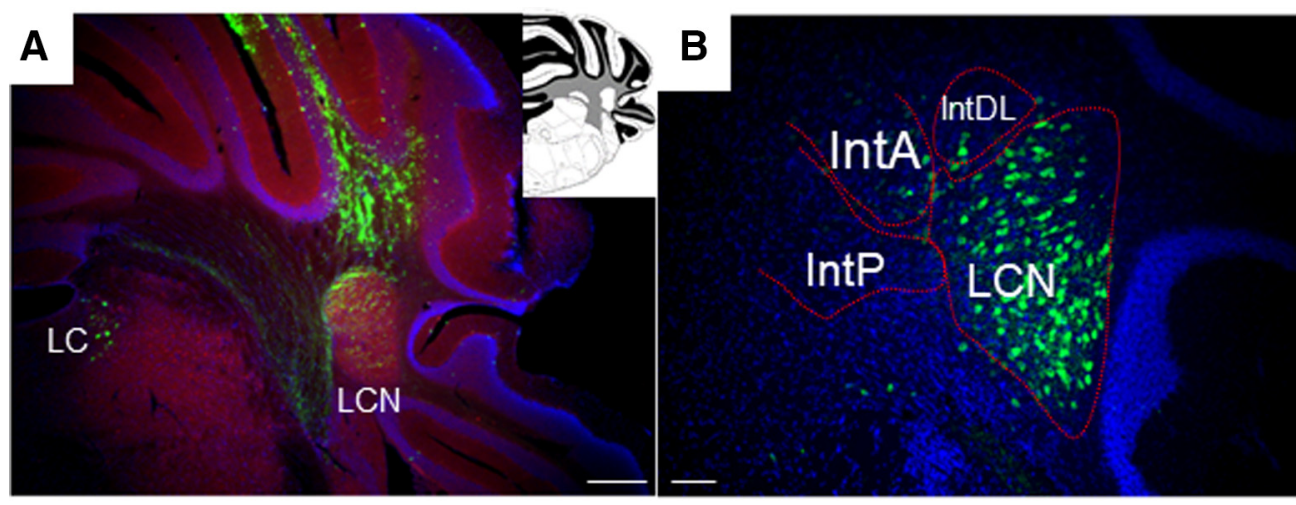

C Fixed Ratio 1 (Instrumental Learning)

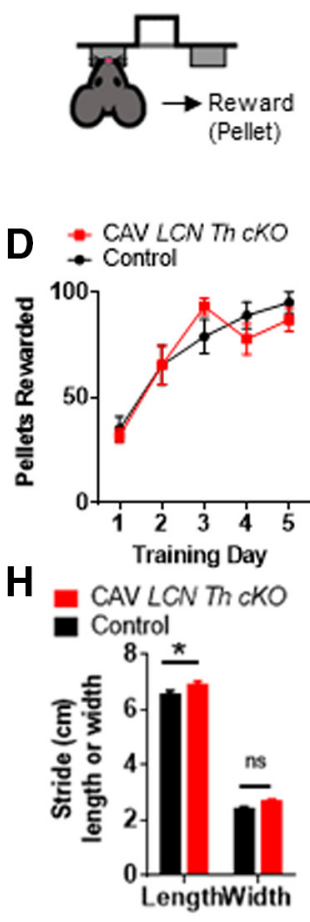

8s Delay (WM Maintenance)

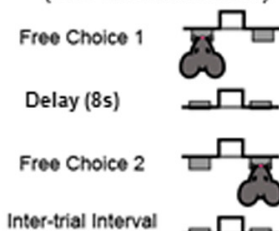
(20s)
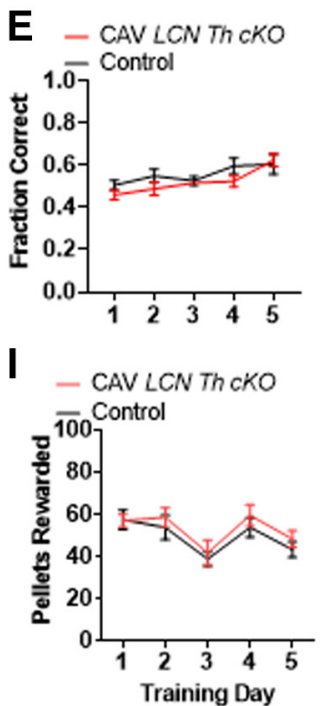

16s Delay (WM Maintenance)

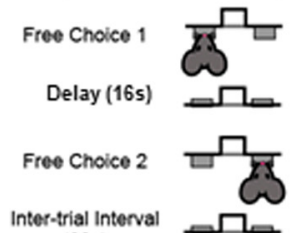
(20s)

F - CAV LCN Th CKO

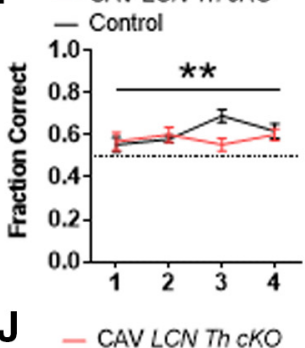

J

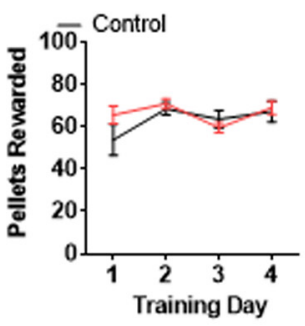

Reversal

(Behavioral Flexibility)

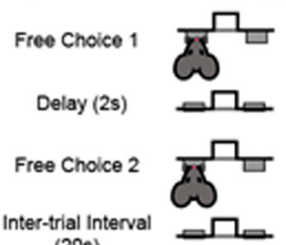

(20s)

G

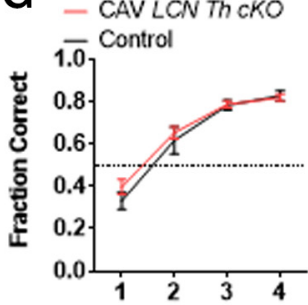

K

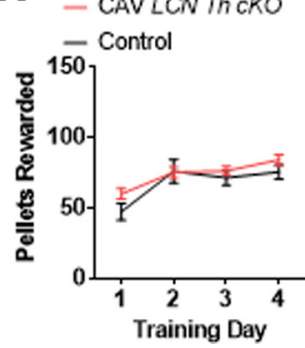

Figure 10. Viral injection controls for CAV experiments, and cognitive deficits seen in LCN-Th-CKO mice are not because of sensory, motor, or anxiety phenotypes. $A$, CAV-zsGreen injection into LCN (red represents blank; blue represents DAPI; green represents zsGreen). Inset, Coronal schematic of cerebellum at rostral LCN. B, AAV-DI0-GFP injected into LCN of Vglut2-Cre mouse (red represents blank; blue represents DAPl; green represents zsGreen). LatPC, LCN, parvicellular; IntA, interposed cerebellar nucleus, anterior; IntP, interposed cerebellar nucleus, posterior; IntDL, interposed cerebellar nucleus, dorsal hump. A, Inset, Adapted from Franklin and Paxinos (2013). C, Schematic of instrumental learning, and operant-based delayed alternation test for working memory at $8 \mathrm{~s}, 16 \mathrm{~s}$, and reversal. Adapted from Beas et al. (2017). LCN-Th-CKO mice have no changes in performance on an FR1 instrumental learning (lever training) schedule (D). $N=10$ or 11 per group. LCN-Th-CKO mice showed no differences in performance at $8 \mathrm{~s}(\boldsymbol{E}, I)$, a small, but significant, reduction in performance on the $16 \mathrm{~s}$ version of delayed alternation, as measured by fraction of correct alterations $(\boldsymbol{F})$ (but not pellets rewarded, $\boldsymbol{I}$ ), and no differences in performance on delayed alternation reversal $(\boldsymbol{G}, \boldsymbol{K})$. $N=7$ in each group. $\boldsymbol{H}, \mathrm{LCN}-\mathrm{Th}$ - $\mathrm{CKO}$ mice had a small, but significant, increase in hind stride length (but not stride width) on gait analysis. ${ }^{*} p<0.05$ (unpaired Student's $t$ test). $* * p<0.01$. ns, not significant.

(molecular layer of CCtx, LCN, IN, IO) known for mediating associative learning (Paredes et al., 2009; Heffley et al., 2018; Locke et al., 2018; Kostadinov et al., 2019). LC provides a large projection ( $\sim 12 \%$ of its total $\mathrm{TH}^{+}$cells) to the $\mathrm{LCN}$ (with sparse divergent innervation of nearby CCtx, but not elsewhere in the brain), with projections arising from middle and caudal zones of LC and, to a lesser extent, the rostral LC and subcoeruleus nucleus. We failed to find divergent LC projections in the rest of the brain, which could be because either (1) unlike the CCtx, the LCN does not receive divergent LC axons; or (2) technical limitations of our viral approach limit projection visibility (e.g., tropisms for different cell types, efficiency of retrograde transport/ transduction). Stimulation of LC elicited a transient catecholamine signal in the LCN, which was potentiated by adrenergic $\alpha-2$ receptor blockade, but not D2R blockade. Behavioral experiments indicated that LCN catecholamines modulate the cognitive behaviors we looked at (PPI, fear conditioning, delayed alternation, response inhibition), but not motor, motor learning, or sensory functions. Finally, to mimic the activation of $\mathrm{G}_{\mathrm{i} / \mathrm{o}^{-}}$ coupled catecholamine GPCRs, and to further disentangle whether our experimental approach affected the LCN versus other parts of the brain, inhibition of VGlut $2^{+}$LCN output neurons with DREADDs facilitated learning of the same delayed alternation task in which $\mathrm{LCN}-\mathrm{Th}$-cKO mice showed deficits. 
A

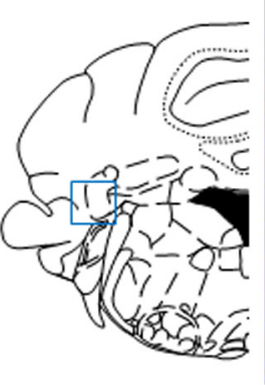

E

Fixed Ratio 1

(Instrumental Learning)

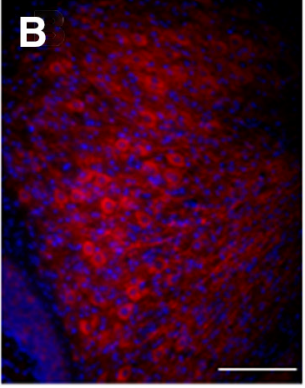

Delayed Alternation: 2s

Working Memory (WM) Learning)

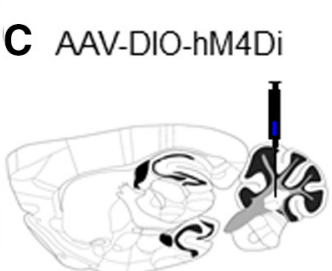

Vglut2-Cre mice

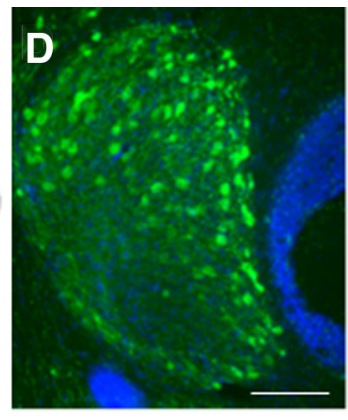

$16 s$ Delay

8s Delay (WM Maintenance)

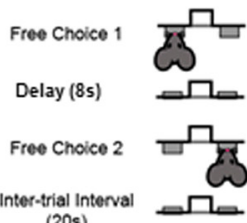

(20s) - Vgiut2-Cre::hM4DiLCN
- Control
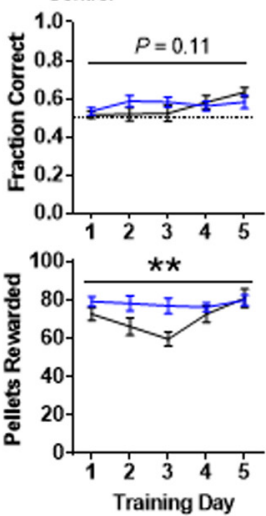

(WM Maintenance)

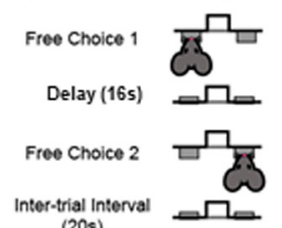

(20s)

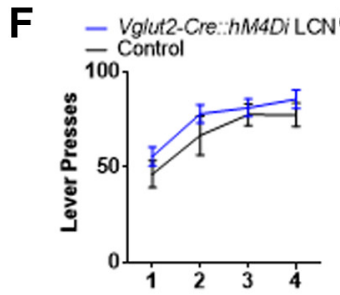

J

Reversal:2s (Behavioral Flexibility)

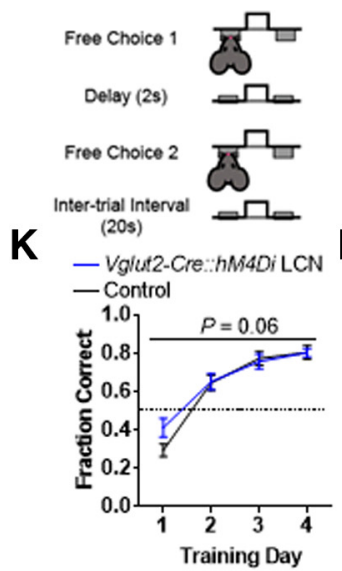

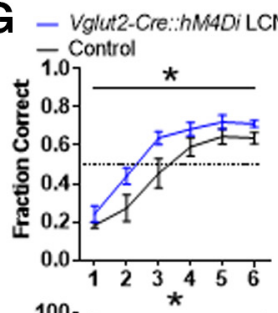
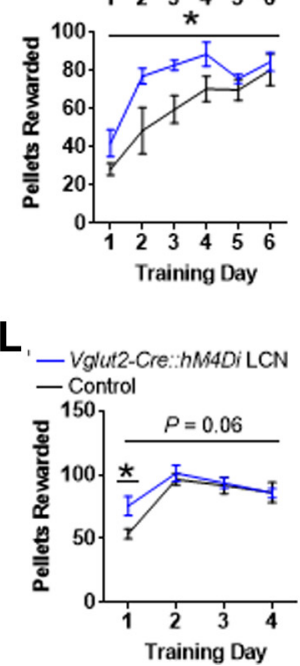

M

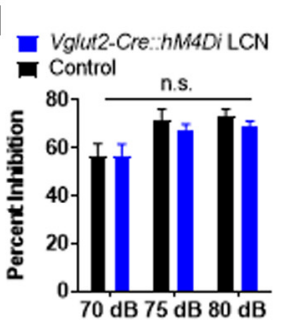

- Vglut2-Cre::hM4DiLCN - Control
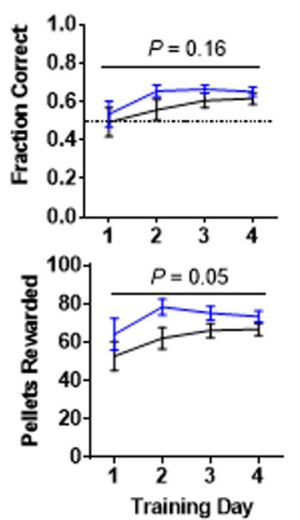

N Vglut2-Cre::hM4DiLCN

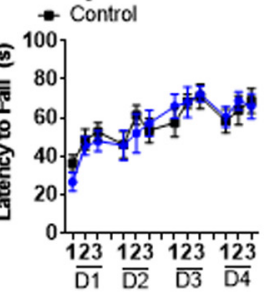

Figure 11. Chemogenetic inhibition of VGlut2 ${ }^{+}$neurons in the LCN results in improved cognitive performance on the delayed alternation working memory task, but not sensory, sensorimotor gating, or motor deficits. A, Schematic for localization of $L C N$ in coronal section. Adapted from Franklin and Paxinos (2013). B, DA D2R staining in large neurons of the LCN. Red represents DA D2R. Blue represents DAPI. Scale bar, $250 \mu \mathrm{m}$. C, Schematic for AAV-DI0-hM4Di viral injection into Vglut2-Cre mice into LCN to generate Vglut2-Cre::hM4Di LCN mice. D, Staining of hM4DiGFP in green channel in LCN of Vglut2-Cre::hM4Di LCN mice. Green represents GFP. Blue represents DAPI. Scale bar, $250 \mu \mathrm{m}$. $\boldsymbol{E}$, Schematic of instrumental learning and operant form of delayed alternation test for working memory. $\boldsymbol{F}$, Performance between Vglut2-Cre::hM4Di LCN mice (blue, $N=8$ ) and AAV-DIO-GFP injected littermate controls (black, $N=7$ ) on an FR1 instrumental learning (lever training) schedule shows no difference between groups. G, Top, Performance between Vglut2-Cre::hM4Di LCN mice and AAV-DIO-GFP injected littermate controls in delayed alternation with $2 \mathrm{~s}$ delay, as measured by fraction of correct alternations. $N=7$ or 8 in each group. There was an effect of training, $F_{(5,65)}=70.45(p<0.0001)$ and effect of viral group, $F_{(1,13)}=6.23,\left({ }^{*} p<0.03\right)$, but no effect of the interaction between group and training, $F_{(5,65)}=1.34(p=0.26)$, two-way repeated-measures ANOVA. Bottom, Performance between Vglut2Cre::hM4Di LCN mice and AAV-DI0-GFP injected littermate controls in delayed alternation with $2 \mathrm{~s}$ delay, as measured by pellets rewarded. $N=7$ or 8 in each group. There was an effect of training, $F_{(5,65)}=21.14(p<0.0001)$ and effect of group, $F_{(1,13)}=7.76\left({ }^{*} p<0.02\right)$, but no effect of the interaction between group and training, $F_{(5,65)}=1.64(p=0.17)$, two-way repeatedmeasures ANOVA. $\boldsymbol{H}$, Top, Performance between Vglut2-Cre::hM4Di LCN mice and AAV-DI0-GFP injected littermate controls in delayed alternation with $8 \mathrm{~s}$ delay, as measured by fraction of correct alternations. $N=7$ or 8 in each group. There was an effect of training, $F_{(4,52)}=2.9(p<0.05)$, but no effect of group, $F_{(1,13)}=0.35(p=0.56)$, or the interaction between group and training, $F_{(4,52)}=2.01(p=0.11)$, two-way repeated-measures ANOVA. Bottom, Performance between Vglut2-Cre::hM4Di LCN mice and AAV-DI0-GFP injected littermate controls in delayed alternation with $8 \mathrm{~s}$ delay, as measured by pellets rewarded. $N=7$ or 8 in each group. There was an effect of training, $F_{(4,52)}=7.71(p=0.0002)$ and effect of the interaction between group and training, $F_{(4,52)}=4.99(* * p<0.002)$, but no effect of group, $F_{(1,13)}=3.26(p=0.094)$, two-way repeated-measures ANOVA. I, Top, Performance between Vglut2-Cre::hM4Di LCN mice and AAV-DI0-GFP injected littermate controls in delayed alternation with $16 \mathrm{~s}$ delay, as measured by fraction of correct alternations. $N=7$ or 8 in each group. There was no effect of training, $F_{(3,39)}=3.64(p=0.06)$, no effect of group, $F_{(1,13)}=2.26(p=0.16)$, and no effect of the interaction between group and training, $F_{(3,39)}=0.22(p=0.88)$, two-way repeated-measures ANOVA. Bottom, Performance between Vglut2-Cre::hM4Di LCN mice and AAV-DIO-GFP injected littermate controls in delayed alternation with $16 \mathrm{~s}$ delay, as measured by pellets rewarded. $N=7$ or 8 in each group. There was no effect of training, $F_{(3,39)}=3.56(p=0.064)$, no effect of group, $F_{(1,13)}=6.2(p=0.05)$, and no effect of the interaction between group and training, $F_{(3,39)}=0.44$ 
These phenotypes are different from Pcp2-Cre; $T h^{\text {lox/lox }}$ mice, in which $T h$ is specifically deleted from PCs: Pcp2-Cre; $T h^{l o x / l o x}$ mice show normal PPI, still learn to freeze to $\mathrm{CS}^{+}$, but do not discriminate well between $\mathrm{CS}^{+}$and $\mathrm{CS}^{-}$tones in the same fear conditioning task; furthermore, they perform normally on the $2 \mathrm{~s}$ delayed alternation, but not a difficult reversal of this task (Locke et al., 2020). Pcp2-Cre; $T h^{l o x / l o x}$ mice show deficits in response inhibition (Locke et al., 2020); therefore, this same phenotype in LCN-Th-cKO mice is more likely attributed to $\mathrm{KO}$ of Th expression in PCs. Pcp2-Cre; $T h^{l o x} /$ lox mice likely had Th deletion in PCs starting during postnatal day 6 (Zhang et al., 2004), when compensatory changes in postnatal developmental processes (e.g., dendritogenesis, synaptogenesis) could occur and reduce the severity of behavioral phenotypes we saw in LCN-Th-cKO mice. In LCN-Th-cKO mice, compensatory developmental changes are avoided, and likely resulted in a more significant phenotype. Nevertheless, different sources of cerebellar catecholamines may have different roles in mediating cognition in different domains.

The role of LCN catecholamines in cognition, in the context of cerebellar structure and function, is likely to be complex. The cerebellum consists of uniform circuit motifs with PCs providing strong inhibitory input to $\mathrm{CN}$ neurons. Given this uniformity, it is notable that there are regional differences in TH fibers in CCtx and $\mathrm{CN}$, as well as $\mathrm{TH}^{+}$PCs (Locke et al., 2020). CN neurons generate the final cerebellar output: spiking activity, which is both temporally and spatially controlled precisely by strongly inhibitory PC inputs (Gauck and Jaeger, 2000; Fujita et al., 2020). $\mathrm{CN}$ play key roles in acquisition and long-term retention of memory of cerebellar-dependent conditioned responses (Shutoh et al., 2006; Pakaprot et al., 2009), which is consistent with specific deficits we observed in associative learning in fear conditioning and learning of delayed alternation in LCN-Th-cKO mice.

$\mathrm{CN}$ organization is also important in the appraisal of catecholamine modulation of cognitive function. For example, MN

\footnotetext{
$(p=0.73)$, two-way repeated-measures ANOVA. J, Schematic of delayed alternation reversal test for working memory at 2 s. $\boldsymbol{K}$, Performance between Vglut2-Cre::hM4Di LCN mice and AAV-DIO-GFP injected littermate controls in delayed alternation reversal with $2 s$ delay, as measured by fraction of correct alternations. $N=7$ or 8 in each group. There was an effect of training, $F_{(3,39)}=117.7(p<0.0001)$, but no effect of group, $F_{(1,13)}=0.42(p=0.53)$ and no effect of the interaction between group and training, $F_{(3,39)}=2.69(p=0.06)$, two-way repeated-measures ANOVA. L, Performance between Vglut2-Cre::hM4Di LCN mice and AAVDI0-GFP injected littermate controls in delayed alternation reversal with $2 \mathrm{~s}$ delay, as measured by pellets rewarded. $N=7$ or 8 in each group. There was an effect of training, $F_{(3,39)}=23.39(p<0.0001)$, no effect of group, $F_{(1,13)}=1.22(p=0.29)$, and no effect of the interaction between group and training, $F_{(3,39)}=2.67(p=0.06)$, two-way repeatedmeasures ANOVA. On post hoc analysis (Sidak's multiple comparisons test), Vglut2-Cre::hM4Di LCN mice did receive significantly more pellets on the first day of delayed alternation reversal. ${ }^{*} p<0.05$. Vglut2-Cre:.:hM4Di LCN mice have no changes relative to controls in prepulse inhibition of the acoustic startle reflex $(\boldsymbol{M})$, on accelerating rotarod over $5 \mathrm{~d}$ of training: no difference observed between groups or effect of interaction with training, $N=7$ or 8 per group $(\boldsymbol{N})$. ns, not significant.
}

\section{$\leftarrow$}

neuronal types connect with a specific set of PCs and IO neurons (Fujita et al., 2020), which may have important implications given the differential innervation by $\mathrm{TH}^{+}$fibers of cerebellar regions we observed. Areas with high TH expression, in general, correlate to regions we previously showed to be characterized by low numbers of $\mathrm{TH}^{+}$PCs (Locke et al., 2020), raising the possibility that NE and DA have differing roles in different cerebellar regions. Furthermore, the rostrocaudal gradient of TH expression we observed in LCN is consistent and complementary to the localization of $\mathrm{LCN} \mathrm{D1R}{ }^{+}$neurons we previously observed (Locke et al., 2018). Each CN neuronal type innervates a distinct collection of downstream targets (Fujita et al., 2020), their projection patterns include both excitatory and inhibitory neuronal subtypes, and project to brain regions associated with motor and nonmotor functions (Locke et al., 2018; Fujita et al., 2020). CN terminal fields are likely to be complex as well; in the VTA, for example, a region that receives input from CN (Rogers et al., 2011; Locke et al., 2018; Carta et al., 2019), DA neurons are primarily innervated by local inhibitory neurons and excitatory inputs from elsewhere in the brain, whereas local VTA inhibitory neurons are primarily innervated by inhibitory inputs from elsewhere (Soden et al., 2020). PCs provide the majority of synapses on CN neurons (Palkovits et al., 1977; de Zeeuw and Berrebi, 1995), but $>25 \%$ of synaptic inputs come from sources, such as climbing fibers, mossy fibers from brainstem pre-CN, and local interneurons. Inhibition of CN neurons likely also acts in balance with excitatory inputs (Gauck and Jaeger, 2000) from the IO (providing sensory information), basilar pontine nuclei inputs (providing efference copy from cerebral cortex), and other preCN (including excitatory inputs from LC) (Fung et al., 1994) and VTA (Ikai et al., 1992). Catecholamines modulate cerebellar function at several levels: NE directly modulates PC mean firing rate bidirectionally (Hoffer et al., 1971; Basile and Dunwiddie, 1984; Guo et al., 2016), modulates climbing fiber-PC synapse plasticity (Carey and Regehr, 2009) and parallel fiber-CF synapses (Lippiello et al., 2015), which may directly regulate output from $\mathrm{CN}$, via inhibitory $\mathrm{PC}-\mathrm{CN}$ synapses. $\mathrm{TH}^{+} \mathrm{PCs}$ regulate their own excitability by releasing DA in an autocrine/paracrine fashion from dendrites (Y. S. Kim et al., 2009). Catecholamines act on CN neurons via DA and NE receptors (Nicholas et al., 
1993a,b; Di Mauro et al., 2003, 2013; Locke et al., 2018). These may induce canonical and noncanonical GPCR signaling, resulting in altered excitability of $\mathrm{CN}$ output neurons, and alter cognitive cerebellar outputs. We summarize the manipulations we have performed for this and previous reports (Fig. 12) and propose that reduced catecholamine release in $\mathrm{LCN}$ will reduce excitability of the largely inhibitory population of $\mathrm{D} 1 \mathrm{R}^{+}$neurons and increase excitability of Vglut $2^{+}$output neurons; increased LCN catecholamines will result in increased D1 $\mathrm{R}^{+}$neuron excitability and reduced Vglut2 ${ }^{+}$neuron activity. The cerebellum optimizes kinetic outcomes by comparing a motor plan with sensorimotor feedback to make adjustments (Kawato and Gomi, 1992). In the context of decision-making, the cerebellum may optimize valuation, temporal, and probabilistic discounting in the context of midbrain-dependent associative learning of avoidance and approach, as well as exert influence over the balance between exploitative and exploration strategies in neocortical networks.

The LCN has DA receptors, but the source of DA is not clear. In primates, there is robust distinction between cerebellar DATand DBH-positive axons (Melchitzky and Lewis, 2000). Distinct $\mathrm{DA}$ and NE uptake mechanisms into synaptosomes isolated from mouse cerebellum exist (Efthimiopoulos et al., 1991). All CN have DAT-like binding (Delis et al., 2004, 2008); the source of this may be from DAT ${ }^{+}$PCs (Y. S. Kim et al., 2009). We did not find other extrinsic sources of LCN catecholamines arising from VTA, CA2/A2, SNc, DR, or retrorubral fields. Cerebellar projections from the noradrenergic brainstem nuclei exist (Robertson et al., 2013), but these may innervate other regions in addition to LCN. VTA $\rightarrow \mathrm{LCN}$ projections in rat are glutamatergic (Ikai et al., 1992), and DAT-negative, $\mathrm{TH}^{+}$glutamatergic projections from VTA exist elsewhere (Zell et al., 2020); thus, it is possible TH deletion from other cells innervating the LCN may have other unknown effects, such as reducing L-DOPA, which is proposed to be a neurotransmitter (Goshima et al., 2019). Another possible source of DA is the LC. The LC releases DA in the hippocampus (C. C. Smith and Greene, 2012; Laatikainen et al., 2013; Kempadoo et al., 2016; Takeuchi et al., 2016). Furthermore, we showed that LCN receives input from the caudal LC, a region of LC which also innervates the hippocampus (Loughlin et al., 1986b).

Currently, the nature of the catecholamine signals (i.e., phasic, tonic, or both) that LC or PCs provide to LCN is unknown. Given that LCN projects to LC (Locke et al., 2018), and LC also receives input directly from PCs (Schwarz et al., 2015), it is possible that the cognitive cerebellum could provide similar neural inputs to LC that influence the balance between tonic or phasic NE release from LC throughout the brain.

In conclusion, in this report, we aimed to show that cerebellar catecholamines were necessary to modulate cognitive function. But the question of which $\mathrm{CN}$ is cognition modulated by catecholamines remains: previous reports suggest a gradient of cerebellar nuclear topography with respect to motor and nonmotor function (Fatemi et al., 2012). However, recent reports of circuit anatomy and behavior of the MN suggest otherwise (Fujita et al., 2020; Kelly et al., 2020; Vaaga et al., 2020). Future experiments will examine cognitive modulation by catecholamines in other $\mathrm{CN}$.

\section{References}

Abbott LC, Isaacs KR, Heckroth JA (1996) Co-localization of tyrosine hydroxylase and zebrin II immunoreactivities in Purkinje cells of the mutant mice, tottering and tottering/leaner. Neuroscience 71:461-475.
Arnsten AF (2006a) Fundamentals of attention-deficit/hyperactivity disorder: circuits and pathways. J Clin Psychiatry 67: 7-12.

Arnsten AF (2006b) Stimulants: therapeutic actions in ADHD. Neuropsychopharmacology 31:2376-2383.

Arnsten AF, Li BM (2005) Neurobiology of executive functions: catecholamine influences on prefrontal cortical functions. Biol Psychiatry 57:1377-1384.

Aston-Jones G, Cohen JD (2005) An integrative theory of locus coeruleusnorepinephrine function: adaptive gain and optimal performance. Annu Rev Neurosci 28:403-450.

Aston-Jones G, Waterhouse B (2016) Locus coeruleus: from global projection system to adaptive regulation of behavior. Brain Res 1645:75-78.

Basile AS, Dunwiddie TV (1984) Norepinephrine elicits both excitatory and inhibitory responses from Purkinje cells in the in vitro rat cerebellar slice. Brain Res 296:15-25.

Beas BS, McQuail JA, Ban Uelos C, Setlow B, Bizon JL (2017) Prefrontal cortical GABAergic signaling and impaired behavioral flexibility in aged F344 rats. Neuroscience 345:274-286.

Berridge CW, Devilbiss DM, Andrzejewski ME, Arnsten AF, Kelley AE, Schmeichel B, Hamilton C, Spencer RC (2006) Methylphenidate preferentially increases catecholamine neurotransmission within the prefrontal cortex at low doses that enhance cognitive function. Biol Psychiatry 60:1111-1120.

Bickford P, Heron C, Young DA, Gerhardt GA, De La Garza R (1992) Impaired acquisition of novel locomotor tasks in aged and norepinephrine-depleted F344 rats. Neurobiol Aging 13:475-481.

Bloom FE, Hoffer BJ, Siggins GR (1971) Studies on norepinephrine-containing afferents to Purkinje cells of art cerebellum: I. Localization of the fibers and their synapses. Brain Res 25:501-521.

Bostan AC, Dum RP, Strick PL (2010) The basal ganglia communicate with the cerebellum. Proc Natl Acad Sci USA 107:8452-8456.

Carey MR, Regehr WG (2009) Noradrenergic control of associative synaptic plasticity by selective modulation of instructive signals. Neuron 62:112122.

Carta I, Chen CH, Schott AL, Dorizan S, Khodakhah K (2019) Cerebellar modulation of the reward circuitry and social behavior. Science 363: eaav0581.

Carter ME, Soden ME, Zweifel LS, Palmiter RD (2013) Genetic identification of a neural circuit that suppresses appetite. Nature 503:111-114.

Cartford MC, Samec A, Fister M, Bickford PC (2004) Cerebellar norepinephrine modulates learning of delay classical eyeblink conditioning: evidence for post-synaptic signaling via PKA. Learn Mem 11:732-737.

Caston J, Jones N, Stelz T (1995a) Role of preoperative and postoperative sensorimotor training on restoration of the equilibrium behavior in adult mice following cerebellectomy. Neurobiol Learn Mem 64:195-202.

Caston J, Vasseur F, Stelz T, Chianale C, Delhaye-Bouchaud N, Mariani J (1995b) Differential roles of cerebellar cortex and deep cerebellar nuclei in the learning of the equilibrium behavior: studies in intact and cerebellectomized lurcher mutant mice. Brain Res Dev Brain Res 86:311-316.

Cendelin J, Voller J, Vozeh F (2010) Ataxic gait analysis in a mouse model of the olivocerebellar degeneration. Behav Brain Res 210:8-15.

Davis M, Gendelman DS, Tischler MD, Gendelman PM (1982) A primary acoustic startle circuit: lesion and stimulation studies. J Neurosci 2:791805.

Delis F, Mitsacos A, Giompres P (2004) Dopamine receptor and transporter levels are altered in the brain of Purkinje cell degeneration mutant mice. Neuroscience 125:255-268.

Delis F, Mitsacos A, Giompres P (2008) Pharmacological characterization and anatomical distribution of the dopamine transporter in the mouse cerebellum. Cerebellum 7:242-251.

de Zeeuw CI, Berrebi AS (1995) Postsynaptic targets of Purkinje cell terminals in the cerebellar and vestibular nuclei of the rat. Eur J Neurosci 7:2322-2333.

Di Mauro M, Fretto G, Caldera M, Li Volsi G, Licata F, Ciranna L, Santangelo F (2003) Noradrenaline and 5-hydroxytryptamine in cerebellar nuclei of the rat: functional effects on neuronal firing. Neurosci Lett 347:101-105.

Di Mauro M, Li Volsi G, Licata F (2013) Noradrenergic control of neuronal firing in cerebellar nuclei: modulation of GABA responses. Cerebellum 12:350-361.

Dum RP, Strick PL (2003) An unfolded map of the cerebellar dentate nucleus and its projections to the cerebral cortex. J Neurophysiol 89:634-639. 
Efthimiopoulos S, Giompres P, Valcana T (1991) Kinetics of dopamine and noradrenaline transport in synaptosomes from cerebellum, striatum and frontal cortex of normal and reeler mice. J Neurosci Res 29:510-519.

Fatemi SH, Aldinger KA, Ashwood P, Bauman ML, Blaha CD, Blatt GJ, Chauhan A, Chauhan V, Dager SR, Dickson PE, Estes AM, Goldowitz D, Heck DH, Kemper TL, King BH, Martin LA, Millen KJ, Mittleman G, Mosconi MW, Persico AM, et al. (2012) Consensus paper: pathological role of the cerebellum in autism. Cerebellum 11:777-807.

Franklin KB, Paxinos G (2013) Paxinos and Franklin's The mouse brain in stereotaxic coordinates, Ed 4. Amsterdam: Academic.

Freedman M (1994) Frontal and parietal lobe dysfunction in depression: delayed alternation and tactile learning deficits. Neuropsychologia 32:1015-1025.

Freedman M, Oscar-Berman M (1986a) Bilateral frontal lobe disease and selective delayed response deficits in humans. Behav Neurosci 100:337342.

Freedman M, Oscar-Berman M (1986b) Selective delayed response deficits in Parkinson's and Alzheimer's disease. Arch Neurol 43:886-890.

Freedman R (1977) Interactions of antipsychotic drugs with norepinephrine and cerebellar neuronal circuitry: implications for the psychobiology of psychosis. Biol Psychiatry 12:181-197.

Freedman R, Hoffer BJ, Woodward DJ, Puro D (1977) Interaction of norepinephrine with cerebellar activity evoked by mossy and climbing fibers. Exp Neurol 55:269-288.

Fristrup N, Birkenkamp-Demtröder K, Reinert T, Sanchez-Carbayo M, Segersten U, Malmström PU, Palou J, Alvarez-Múgica M, Pan CC, Ulhøi BP, Borre M, Ørntoft TF, Dyrskjøt L (2013) Multicenter validation of cyclin D1, MCM7, TRIM29, and UBE2C as prognostic protein markers in non-muscle-invasive bladder cancer. Am J Pathol 182:339-349.

Fujii T, Sakai M, Nagatsu I (1994) Immunohistochemical demonstration of expression of tyrosine hydroxylase in cerebellar Purkinje cells of the human and mouse. Neurosci Lett 165:161-163.

Fujita H, Kodama T, du Lac S (2020) Modular output circuits of the fastigial nucleus for diverse motor and nonmotor functions of the cerebellar vermis. Elife 9:e58613.

Fung SJ, Reddy VK, Liu RH, Wang Z, Barnes CD (1994) Existence of glutamate in noradrenergic locus coeruleus neurons of rodents. Brain Res Bull 35:505-512.

Gao Z, Proietti-Onori M, Lin Z, Ten Brinke MM, Boele HJ, Potters JW, Ruigrok TJ, Hoebeek FE, de Zeeuw CI (2016) Excitatory cerebellar nucleocortical circuit provides internal amplification during associative conditioning. Neuron 89:645-657.

Gauck V, Jaeger D (2000) The control of rate and timing of spikes in the deep cerebellar nuclei by inhibition. J Neurosci 20:3006-3016.

Gore BB, Zweifel LS (2013) Genetic reconstruction of dopamine D1 receptor signaling in the nucleus accumbens facilitates natural and drug reward responses. J Neurosci 33:8640-8649.

Gore BB, Soden ME, Zweifel LS (2013) Manipulating gene expression in projection-specific neuronal populations using combinatorial viral approaches. Curr Protoc Neurosci 65:4.35.1-4.35.20.

Goshima Y, Masukawa D, Kasahara Y, Hashimoto T, Aladeokin AC (2019) L-DOPA and its receptor GPR143: implications for pathogenesis and therapy in Parkinson's disease. Front Pharmacol 10:1119.

Grzanna R, Molliver ME (1980) The locus coeruleus in the rat: an immunohistochemical delineation. Neuroscience 5:21-40.

Guo A, Feng JY, Li J, Ding N, Li YJ, Qiu DL, Piao RL, Chu CP (2016) Effects of norepinephrine on spontaneous firing activity of cerebellar Purkinje cells in vivo in mice. Neurosci Lett 629:262-266.

Heffley W, Hull C (2019) Classical conditioning drives learned reward prediction signals in climbing fibers across the lateral cerebellum. Elife 8: e46764.

Heffley W, Song EY, Xu Z, Taylor BN, Hughes MA, McKinney A, Joshua M, Hull C (2018) Coordinated cerebellar climbing fiber activity signals learned sensorimotor predictions. Nat Neurosci 21:1431-1441.

Heskje J, Heslin K, De Corte BJ, Walsh KP, Kim Y, Han S, Carlson ES, Parker KL (2020) Cerebellar D1DR-expressing neurons modulate the frontal cortex during timing tasks. Neurobiol Learn Mem 170:107067.

Hess EJ, Wilson MC (1991) Tottering and leaner mutations perturb transient developmental expression of tyrosine hydroxylase in embryologically distinct Purkinje cells. Neuron 6:123-132.

Hoffer BJ, Siggins GR, Bloom FE (1971) Studies on norepinephrine-containing afferents to Purkinje cells of rat cerebellum: II. Sensitivity of Purkinje cells to norepinephrine and related substances administered by microiontophoresis. Brain Res 25:523-534.

Hokfelt T, Fuxe K (1969) Cerebellar monoamine nerve terminals, a new type of afferent fibers to the cortex cerebelli. Exp Brain Res 9:63-72.

Houck BD, Person AL (2015) Cerebellar premotor output neurons collateralize to innervate the cerebellar cortex. J Comp Neurol 523:2254-2271.

Ikai Y, Takada M, Shinonaga Y, Mizuno N (1992) Dopaminergic and nondopaminergic neurons in the ventral tegmental area of the rat project, respectively, to the cerebellar cortex and deep cerebellar nuclei. Neuroscience 51:719-728.

Jackson CR, Ruan GX, Aseem F, Abey J, Gamble K, Stanwood G, Palmiter RD, Iuvone PM, McMahon DG (2012) Retinal dopamine mediates multiple dimensions of light-adapted vision. J Neurosci 32:9359-9368.

Kawato M, Gomi H (1992) A computational model of four regions of the cerebellum based on feedback-error learning. Biol Cybern 68:95-103.

Kelly E, Meng F, Fujita H, Morgado F, Kazemi Y, Rice LC, Ren C, Escamilla CO, Gibson JM, Sajadi S, Pendry RJ, Tan T, Ellegood J, Basson MA, Blakely RD, Dindot SV, Golzio C, Hahn MK, Katsanis N, Robins DM, et al. (2020) Regulation of autism-relevant behaviors by cerebellar-prefrontal cortical circuits. Nat Neurosci 23:1102-1110.

Kempadoo KA, Mosharov EV, Choi SJ, Sulzer D, Kandel ER (2016) Dopamine release from the locus coeruleus to the dorsal hippocampus promotes spatial learning and memory. Proc Natl Acad Sci USA 113:14835-14840

Kim SG, Uğurbil K, Strick PL (1994) Activation of a cerebellar output nucleus during cognitive processing. Science 265:949-951.

Kim YS, Shin JH, Hall FS, Linden DJ (2009) Dopamine signaling is required for depolarization-induced slow current in cerebellar Purkinje cells. J Neurosci 29:8530-8538.

Kostadinov D, Beau M, Blanco-Pozo M, Häusser M (2019) Predictive and reactive reward signals conveyed by climbing fiber inputs to cerebellar Purkinje cells. Nat Neurosci 22:950-962.

Kubrusly RC, Ventura AL, de Melo Reis RA, Serra GC, Yamasaki EN, Gardino PF, de Mello MC, de Mello FG (2007) Norepinephrine acts as D1-dopaminergic agonist in the embryonic avian retina: late expression of beta1-adrenergic receptor shifts norepinephrine specificity in the adult tissue. Neurochem Int 50:211-218.

Kuper M, Dimitrova A, Thurling M, Maderwald S, Roths J, Elles HG, Gizewski ER, Ladd ME, Diedrichsen J, Timmann D (2011) Evidence for a motor and a nonmotor domain in the human dentate nucleus: an fMRI study. Neuroimage 54:2612-2622.

Laatikainen LM, Sharp T, Harrison PJ, Tunbridge EM (2013) Sexually dimorphic effects of catechol-O-methyltransferase (COMT) inhibition on dopamine metabolism in multiple brain regions. PLoS One 8:e61839.

Landis SC, Bloom FE (1975) Ultrastructural identification of noradrenergic boutons in mutant and normal mouse cerebellar cortex. Brain Res 96:299-305.

Landis SC, Shoemaker WJ, Schlumpf M, Bloom FE (1975) Catecholamines in mutant mouse cerebellum: fluorescence microscopic and chemical studies. Brain Res 93:253-266.

Lin CW, Miller TR, Witte DG, Bianchi BR, Stashko M, Manelli AM, Frail DE (1995) Characterization of cloned human dopamine D1 receptor-mediated calcium release in 293 cells. Mol Pharmacol 47:131-139.

Lippiello P, Hoxha E, Volpicelli F, Lo Duca G, Tempia F, Miniaci MC (2015) Noradrenergic modulation of the parallel fiber-Purkinje cell synapse in mouse cerebellum. Neuropharmacology 89:33-42.

Locke TM, Soden ME, Miller SM, Hunker A, Knakal C, Licholai JA, Dhillon KS, Keene CD, Zweifel LS, Carlson ES (2018) Dopamine D1 receptorpositive neurons in the lateral nucleus of the cerebellum contribute to cognitive behavior. Biol Psychiatry 84:401-412.

Locke TM, Fujita H, Hunker A, Johanson SS, Darvas M, du Lac S, Zweifel LS, Carlson ES (2020) Purkinje cell specific knockout of tyrosine hydroxylase impairs cognitive behavior. Front Cell Neurosci 14:228.

Loughlin SE, Foote SL, Bloom FE (1986a) Efferent projections of nucleus locus coeruleus: topographic organization of cells of origin demonstrated by three-dimensional reconstruction. Neuroscience 18:291-306.

Loughlin SE, Foote SL, Grzanna R (1986b) Efferent projections of nucleus locus coeruleus: morphologic subpopulations have different efferent targets. Neuroscience 18:307-319.

Loveland KA, Bachevalier J, Pearson DA, Lane DM (2008) Fronto-limbic functioning in children and adolescents with and without autism. Neuropsychologia 46:49-62. 
Madisen L, Zwingman TA, Sunkin SM, Oh SW, Zariwala HA, Gu H, Ng LL, Palmiter RD, Hawrylycz MJ, Jones AR, Lein ES, Zeng H (2010) A robust and high-throughput Cre reporting and characterization system for the whole mouse brain. Nat Neurosci 13:133-140.

Melchitzky DS, Lewis DA (2000) Tyrosine hydroxylase- and dopamine transporter-immunoreactive axons in the primate cerebellum: evidence for a lobular- and laminar-specific dopamine innervation. Neuropsychopharmacology 22:466-472.

Mittleman G, Goldowitz D, Heck DH, Blaha CD (2008) Cerebellar modulation of frontal cortex dopamine efflux in mice: relevance to autism and schizophrenia. Synapse 62:544-550.

Nagai T, Satoh K, Imamoto K, Maeda T (1981) Divergent projections of catecholamine neurons of the locus coeruleus as revealed by fluorescent retrograde double labeling technique. Neurosci Lett 23:117-123.

Nautiyal KM, Tanaka KF, Barr MM, Tritschler L, Le Dantec Y, David DJ, Gardier AM, Blanco C, Hen R, Ahmari SE (2015) Distinct circuits underlie the effects of 5-HT1B receptors on aggression and impulsivity. Neuron 86:813-826.

Nelson TE, King JS, Bishop GA (1997) Distribution of tyrosine hydroxylaseimmunoreactive afferents to the cerebellum differs between species. J Comp Neurol 379:443-454.

Nicholas AP, Pieribone V, Hokfelt T (1993a) Distributions of mRNAs for alpha-2 adrenergic receptor subtypes in rat brain: an in situ hybridization study. J Comp Neurol 328:575-594.

Nicholas AP, Pieribone VA, Hokfelt T (1993b) Cellular localization of messenger RNA for beta- 1 and beta- 2 adrenergic receptors in rat brain: an in situ hybridization study. Neuroscience 56:1023-1039.

O'Reilly JX, Mesulam MM, Nobre AC (2008) The cerebellum predicts the timing of perceptual events. J Neurosci 28:2252-2260.

Olson L, Fuxe K (1971) On the projections from the locus coeruleus noradrenaline neurons: the cerebellar innervation. Brain Res 28:165-171.

Pakaprot N, Kim S, Thompson RF (2009) The role of the cerebellar interpositus nucleus in short and long term memory for trace eyeblink conditioning. Behav Neurosci 123:54-61.

Palkovits M, Mezey E, Hamori J, Szentagothai J (1977) Quantitative histological analysis of the cerebellar nuclei in the cat: I. Numerical data on cells and on synapses. Exp Brain Res 28:189-209.

Panagopoulos NT, Papadopoulos GC, Matsokis NA (1991) Dopaminergic innervation and binding in the rat cerebellum. Neurosci Lett 130:208212.

Paredes DA, Cartford MC, Catlow BJ, Samec A, Avilas M, George A, Schlunck A, Small B, Bickford PC (2009) Neurotransmitter release during delay eyeblink classical conditioning: role of norepinephrine in consolidation and effect of age. Neurobiol Learn Mem 92:267-282.

Park S, Holzman PS (1992) Schizophrenics show spatial working memory deficits. Arch Gen Psychiatry 49:975-982.

Robertson SD, Plummer NW, de Marchena J, Jensen P (2013) Developmental origins of central norepinephrine neuron diversity. Nat Neurosci 16:1016-1023.

Rodeberg NT, Sandberg SG, Johnson JA, Phillips PE, Wightman RM (2017) Hitchhiker's guide to voltammetry: acute and chronic electrodes for in vivo fast-scan cyclic voltammetry. ACS Chem Neurosci 8:221-234.

Rogers TD, Dickson PE, Heck DH, Goldowitz D, Mittleman G, Blaha CD (2011) Connecting the dots of the cerebro-cerebellar role in cognitive function: neuronal pathways for cerebellar modulation of dopamine release in the prefrontal cortex. Synapse 65:1204-1212.

Roman CW, Derkach VA, Palmiter RD (2016) Genetically and functionally defined NTS to PBN brain circuits mediating anorexia. Nat Commun 7:11905.

Room P, Postema F, Korf J (1981) Divergent axon collaterals of rat locus coeruleus neurons: demonstration by a fluorescent double labeling technique. Brain Res 221:219-230.

Rossi MA, Hayrapetyan VY, Maimon B, Mak K, Je HS, Yin HH (2012) Prefrontal cortical mechanisms underlying delayed alternation in mice. J Neurophysiol 108:1211-1222.

Sacchetti B, Baldi E, Lorenzini CA, Bucherelli C (2002) Cerebellar role in fear-conditioning consolidation. Proc Natl Acad Sci USA 99:8406-8411.

Sacchetti B, Scelfo B, Tempia F, Strata P (2004) Long-term synaptic changes induced in the cerebellar cortex by fear conditioning. Neuron 42:973982
Sacchetti B, Sacco T, Strata P (2007) Reversible inactivation of amygdala and cerebellum but not perirhinal cortex impairs reactivated fear memories. Eur J Neurosci 25:2875-2884

Sánchez-Soto M, Bonifazi A, Cai NS, Ellenberger MP, Newman AH, Ferré S, Yano H (2016) Evidence for noncanonical neurotransmitter activation: norepinephrine as a dopamine D2-like receptor agonist. Mol Pharmacol 89:457-466.

Sanford CA, Soden ME, Baird MA, Miller SM, Schulkin J, Palmiter RD, Clark M, Zweifel LS (2017) A central amygdala CRF circuit facilitates learning about weak threats. Neuron 93:164-178.

Scelfo B, Sacchetti B, Strata P (2008) Learning-related long-term potentiation of inhibitory synapses in the cerebellar cortex. Proc Natl Acad Sci USA 105:769-774.

Schultz W (2013) Updating dopamine reward signals. Curr Opin Neurobiol 23:229-238.

Schwarz LA, Miyamichi K, Gao XJ, Beier KT, Weissbourd B, DeLoach KE, Ren J, Ibanes S, Malenka RC, Kremer EJ, Luo L (2015) Viral-genetic tracing of the input-output organization of a central noradrenaline circuit. Nature 524:88-92.

Shutoh F, Ohki M, Kitazawa H, Itohara S, Nagao S (2006) Memory trace of motor learning shifts transsynaptically from cerebellar cortex to nuclei for consolidation. Neuroscience 139:767-777.

Smith CC, Greene RW (2012) CNS dopamine transmission mediated by noradrenergic innervation. J Neurosci 32:6072-6080.

Smith PF, Brandt T, Strupp M, Darlington CL, Zheng Y (2009) Balance before reason in rats and humans. Ann NY Acad Sci 1164:127-133.

Smith PF, Darlington CL, Zheng Y (2010) Move it or lose it: is stimulation of the vestibular system necessary for normal spatial memory? Hippocampus 20:36-43.

Smith PF, Darlington CL, Zhen Y (2015) The effects of complete vestibular deafferentation on spatial memory and the hippocampus in the rat: the Dunedin experience. Multisens Res 28:461-485.

Soden ME, Chung AS, Cuevas B, Resnick JM, Awatramani R, Zweifel LS (2020) Anatomic resolution of neurotransmitter-specific projections to the VTA reveals diversity of GABAergic inputs. Nat Neurosci 23:968-980.

Steindler DA (1981) Locus coeruleus neurons have axons that branch to the forebrain and cerebellum. Brain Res 223:367-373.

Sunahara RK, Niznik HB, Weiner DM, Stormann TM, Brann MR, Kennedy JL, Gelernter JE, Rozmahel R, Yang YL, Israel Y (1990) Human dopamine D1 receptor encoded by an intronless gene on chromosome 5. Nature 347:80-83.

Takada M, Sugimoto T, Hattori T (1993) Tyrosine hydroxylase immunoreactivity in cerebellar Purkinje cells of the rat. Neurosci Lett 150:61-64.

Takeuchi T, Kiyama Y, Nakamura K, Tsujita M, Matsuda I, Mori H, Munemoto Y, Kuriyama H, Natsume R, Sakimura K, Mishina M (2001) Roles of the glutamate receptor epsilon 2 and delta 2 subunits in the potentiation and prepulse inhibition of the acoustic startle reflex. Eur J Neurosci 14:153-160.

Takeuchi T, Duszkiewicz AJ, Sonneborn A, Spooner PA, Yamasaki M, Watanabe M, Smith CC, Fernandez G, Deisseroth K, Greene RW, Morris RG (2016) Locus coeruleus and dopaminergic consolidation of everyday memory. Nature 537:357-362.

Tellmann S, Bludau S, Eickhoff S, Mohlberg H, Minnerop M, Amunts K (2015) Cytoarchitectonic mapping of the human brain cerebellar nuclei in stereotaxic space and delineation of their co-activation patterns. Front Neuroanat 9:54

Tervo DG, Hwang BY, Viswanathan S, Gaj T, Lavzin M, Ritola KD, Lindo S, Michael S, Kuleshova E, Ojala D, Huang CC, Gerfen CR, Schiller J, Dudman JT, Hantman AW, Looger LL, Schaffer DV, Karpova AY (2016) A designer AAV variant permits efficient retrograde access to projection neurons. Neuron 92:372-382.

Thoma P, Bellebaum C, Koch B, Schwarz M, Daum I (2008) The cerebellum is involved in reward-based reversal learning. Cerebellum 7:433-443

Tsutsumi S, Hidaka N, Isomura Y, Matsuzaki M, Sakimura K, Kano M, Kitamura K (2019) Modular organization of cerebellar climbing fiber inputs during goal-directed behavior. Elife 8:e47021.

Vaaga CE, Brown ST, Raman IM (2020) Cerebellar modulation of synaptic input to freezing-related neurons in the periaqueductal gray. Elife 9: e54302. 
Vanderheyden P, Ebinger G, Kanarek L, Vauquelin G (1986) Epinephrine and norepinephrine stimulation of adenylate cyclase in bovine retina homogenate: evidence for interaction with the dopamine D1 receptor. Life Sci 38:1221-1227.

Versteeg DH, Van Der Gugten J, De Jong W, Palkovits M (1976) Regional concentrations of noradrenaline and dopamine in rat brain. Brain Res 113:563-574.

Vong L, Ye C, Yang Z, Choi B, Chua S Jr, Lowell BB (2011) Leptin action on GABAergic neurons prevents obesity and reduces inhibitory tone to POMC neurons. Neuron 71:142-154.

Wagner MJ, Kim TH, Savall J, Schnitzer MJ, Luo L (2017) Cerebellar granule cells encode the expectation of reward. Nature 544:96-100.

Wanat M, Bonci A, Phillips P (2013) CRF acts in the midbrain to attenuate accumbens dopamine release to rewards but not their predictors. Nat Neurosci 16:383-385.

Watson M, McElligott JG (1983) 6-OHDA induced effects upon the acquisition and performance of specific locomotor tasks in rats. Pharmacol Biochem Behav 18:927-934.
Watson M, McElligott JG (1984) Cerebellar norepinephrine depletion and impaired acquisition of specific locomotor tasks in rats. Brain Res 296:129-138.

Zell V, Steinkellner T, Hollon NG, Warlow SM, Souter E, Faget L, Hunker AC, Jin X, Zweifel LS, Hnasko TS (2020) VTA glutamate neuron activity drives positive reinforcement absent dopamine co-release. Neuron 107:864-873.

Zhang XM, Ng AH, Tanner JA, Wu WT, Copeland NG, Jenkins NA, Huang JD (2004) Highly restricted expression of Cre recombinase in cerebellar Purkinje cells. Genesis 40:45-51.

Zheng Y, Goddard M, Darlington CL, Smith PF (2009a) Long-term deficits on a foraging task after bilateral vestibular deafferentation in rats. Hippocampus 19:480-486.

Zheng Y, Balabhadrapatruni S, Masumura C, Munro O, Darlington CL, Smith PF (2009b) Bilateral vestibular deafferentation causes deficits in a 5-choice serial reaction time task in rats. Behav Brain Res 203:113-117.

Zhuang X, Masson J, Gingrich JA, Rayport S, Hen R (2005) Targeted gene expression in dopamine and serotonin neurons of the mouse brain. J Neurosci Methods 143:27-32. 